\title{
Impact of China's Environmental Decentralization on Carbon Emissions From Energy Consumption: An Empirical Study Based on the Dynamic Spatial Econometric Model
}

\section{Xianzhao Liu}

Hunan University of Science and Technology https://orcid.org/0000-0003-0188-4592

Xu Yang ( $\sim$ yangxu@mail.hnust.edu.cn )

Hunan University of Science and Technology

\section{Research Article}

Keywords: Environmental decentralization, Fiscal decentralization, Carbon emission, Spatial perspective, Dynamic spatial econometric model

Posted Date: September 7th, 2021

DOl: https://doi.org/10.21203/rs.3.rs-732000/v1

License: (c) (1) This work is licensed under a Creative Commons Attribution 4.0 International License. Read Full License

Version of Record: A version of this preprint was published at Environmental Science and Pollution Research on March 30th, 2022. See the published version at https://doi.org/10.1007/s11356-022-18806$\mathrm{x}$. 
1 Impact of China's environmental decentralization on carbon

2 emissions from energy consumption: An empirical study based on

3 the dynamic spatial econometric model

4

5

6

$7 \quad$ *Correspondence: Xu Yang

8 E-mail: yangxu@mail.hnust.edu.cn

9 Mobile phone: +86-15197292263

10

Tel: +86-0731-58290040
Xianzhao Liu, Xu Yang*

\begin{abstract}
School of Resource, Environment and Safety Engineering, Hunan University of Science and Technology,
Xiangtan Hunan 411201, China
\end{abstract}


Impact of China's environmental decentralization on carbon emissions from energy consumption: An empirical study based on the dynamic spatial econometric model

\begin{abstract}
Facing the growing problem of carbon emission pollution, the scientific and reasonable division of environmental management power between governments is the premise and institutional foundation for realizing China's carbon emission reduction target in 2030. Although existing studies have focused on the relationship between Chinese decentralization and carbon emissions, most of them are based on fiscal decentralization indicators to depict China's environmental decentralization, lacking of systematic analysis and empirical test of institutional factors affecting carbon emissions from the perspective of environmental management. In this paper, we directly assess the environmental decentralization degree according to the allocation of environmental management personnel among different levels of government. By incorporating fiscal decentralization indicators, the provincial panel data and dynamic spatial econometric model are used to empirically test the impact of environmental decentralization on carbon emissions from spatial perspective. The study found that: (1) China's provincial carbon emissions have a significant positive spatial autocorrelation, showing a clear trend of high-high, low-low aggregation, and the carbon emissions of the previous period and the current have an obvious positive relationship. (2) At the national level, environmental decentralization, environmental administrative decentralization and environmental monitoring decentralization significantly reduce China's carbon emissions, while environmental supervision decentralization and fiscal decentralization significantly aggravate carbon emissions, which means that China's current environmental decentralization systems are generally conducive to carbon emission governance. The interaction between fiscal decentralization and environmental decentralization with its decomposition indicators significantly promotes carbon emissions, and its impact is related to the category of environmental decentralization, indicating that when local governments have greater environmental management power and fiscal autonomy, the combination of the two will push up carbon emissions. (3) The carbon emission effects of environmental decentralization in different regions are spatially heterogeneous. In the central region, environmental decentralization, environmental administrative decentralization and environmental supervision decentralization can promote carbon emissions apart from environmental monitoring decentralization. In the western region, the carbon emission suppression effect of environmental decentralization, environmental administrative decentralization and environmental monitoring decentralization is stronger than the eastern region, but the inhibitory effect of fiscal
\end{abstract}


43 decentralization and environmental decentralization with its decomposition index interaction on carbon 44 emissions in the eastern region is significantly better than the central and western regions. The above 45 results provide policy ideas and theoretical support for the construction of the environmental management 46 system with long-term carbon emission control in China in terms of regional differences and categories of 47 environmental management power.

48 Keywords Environmental decentralization; Fiscal decentralization; Carbon emission; Spatial perspective; 49 Dynamic spatial econometric model 


\section{Introduction}

With the rapid development of social economy and the increasing energy consumption, the environmental pollution problems in the world have become increasingly prominent. In particular, as the important part of environmental pollution, carbon dioxide emissions (hereinafter referred to as carbon emissions) lead to greenhouse effect and global warming is an indisputable fact. Under such circumstances, reducing greenhouse gas emissions and developing low-carbon economy have become important measures taken by governments to deal with climate change and solve the environmental pollution problem (Zhang et al. 2011). According to BP World Energy Statistics, carbon emissions in China have been on a rapid upward trend since 2000 and reached 9.258 billion tons in 2017, accounting for $27.3 \%$ of total carbon emissions in the world. To improve environmental quality, Chinese government has made a great deal of effective efforts to fulfill national commitments on carbon emission reduction (to reduce carbon dioxide emissions per unit of GDP in 2030 by $60 \%-65 \%$ compared to 2005 , and the proportion of non-fossil energy in total primary energy consumption will reach to 20\%),especially in the "13th Five-Year Plan", China has taken the environmental governance institution reformation, local governments' environmental responsibility implement, and modern environmental management system construction as a basic task. At the same time, several reform initiatives also have been proposed, including the establishment of clear responsibilities and powers, environmental protection supervision and accountability for environmental damage. In recent years, with the reformation of environmental decentralization management institution at different government levels in recent years, local governments, in order to pursue the GDP growth and promotion incentives, often choose to loosen environmental regulations to launch a "bottom-up competition", which in exchange for economic growth at the expense of the environment, and ultimately lead to increase pollution (Lu and Zhang 2016; Bai et al. 2017). At present, research on carbon emissions mainly focuses on measurement, regional differences, influencing factors, and carbon reduction countermeasures. In terms of the factors influencing carbon emissions, most scholars have conducted extensive research on the effects of economic growth, population density, energy structure, industrial structure, technology level, and trade openness on carbon emissions (Zhang et al. 2017; Feng et al. 2017), while less research has been conducted specifically on the institutional factors. And it is undeniable that regional environmental quality (carbon emissions) cannot be independent of institutional factors. If institutional factors, which are closely related to carbon emission reductions, are ignored, it may be difficult to effectively curb the current carbon emissions at high level. Environmental decentralization, as an important part of the environmental management system in central and local governments, is bound to have a significant impact on regional carbon emissions to some extent. However, most of the existing studies (Zhang et al. 2017; Ran et al. 2020; Peng 2016; He 2015; Tian et al. 2018; Xue et al. 2012; Yan 2012; Wang et al. 2014; Ben et al. 2017; Huang 2017; Zhang et al. 2017) concluded that environmental decentralization distorted the supply mode of environmental public goods 
and intensifies competition among local governments, thus creating a significant positive boost to carbon emissions and environmental pollution. It is noteworthy that most of the above-mentioned studies simply characterize environmental decentralization among governments using fiscal decentralization indicators, ignoring the differences between environmental decentralization and fiscal decentralization. In fact, fiscal decentralization reflects more about the economic or political rights divided from central and local governments, while environmental decentralization, with basic public services as its core, mainly reflects the division of powers over environmental management. If we confuse the essential difference between the two and using fiscal decentralization indicators as an approximate substitute for intergovernmental environmental decentralization may lead to a measurement deviation on environmental decentralization, making it difficult to determine the direction and extent of the impact of environmental decentralization on carbon emissions. Furthermore, does the current environmental decentralization have a positive effect (increasing carbon emissions) or a negative effect (decreasing carbon emissions) on carbon emissions in China? Does the existing fiscal decentralization have an impact on this? Should central and local governments centralize or decentralize powers over carbon emission reduction and environmental management? And how to determine the appropriate level of decentralization, all of the above questions need to be answered, but the current research on these issues has not given definite answers, unfortunately. A few scholars have explored the relationship between environmental decentralization and carbon emissions from an empirical perspective (Lu and Zhang 2016; Zhang et al. 2017; Ran et al. 2020) and found that environmental decentralization can significantly increase carbon emissions indirectly through political and economic incentives (Halkos et al. 2013; Xiao et al. 2014), however, they have neglected that both carbon emissions and environmental governance have spillover effects and spatial correlations, and the importance of geospatial correlations in environmental issues has been confirmed by many scholars (Anselin 2001; Maddison 2006; Poon et al. 2006; Hossein et al. 2013). At the same time, the studies mentioned above also ignore the fact that the impact of environmental decentralization on carbon emissions may be spatially heterogeneous across regions with different economic development levels, which is related to the energy consumption structure, economic development level, geographic location and environmental policies. In addition, existing static panel models are less likely to take into account the dynamics and continuity of the explained variables, thus affecting the consistent estimation of the impact of environmental decentralization on carbon emissions. As a result, there is considerable room for improvement in both logic and accuracy of existing studies.

Based on previous studies, this paper constructs various indicators for measuring environmental decentralization from the inherent logic of intergovernmental environmental management power in China, and uses a dynamic spatial measurement model to fully explore and analyze the impact of environmental decentralization on carbon emissions from a spatial perspective, and reveals the environmental institutional mechanisms affecting carbon emissions, so as to find out whether the current environmental management 
in China is indeed aggravating local carbon emissions, and to provide a scientific basis for the Chinese government to improve environmental decentralization management system and promote the realization of carbon emission reduction target in 2030 .

\section{Literature review}

With the increasing severity of environmental problems around the world, scholars have begun to focus on the role of local governments in implementing environmental policies and controlling environmental pollution (Zhang et al. 2017; Luo et al. 2020; Li 2018). Since environmental management as an institutional factor directly affects the environmental quality, it has been a hotspot of research, especially the distribution of power among governmental levels regarding environmental management. As for the environmental management system for carbon emission, it can be traced back to the classic environmental federalism theory (a branch of fiscal federalism) in the 1970s (Zhang et al. 2017), which can be understood as the de facto decentralization of environmental management, that is, the decentralization of environmental management from the central government to local governments so that local governments have autonomy and decision-making power in environmental management affairs. Central to this theory is whether environmental management in a country should be centralized or decentralized, and how responsibility for environmental management should be divided between central and local governments (Cole et al. 2013). At present, the debate over the impact of environmental decentralization on environmental quality or carbon emissions is dominated by three different perspectives: the suppression, the facilitation and the uncertainty theories. The suppression theory, represented by Huang (2017) and Oyono (2005), argues that environmental decentralization management is not conducive to environmental protection, but rather tends to exacerbate environmental pollution in local and neighboring areas, ultimately inhibiting the improvement of environmental quality. Zhang (2011) also concluded that fiscal decentralization is detrimental to reducing environmental pollution from the perspective of carbon emissions. Most scholars who hold this view describe the negative environmental effects of decentralization from the perspective of jurisdictional competition. There are three main reasons for this: (1) Environmental decentralization will give local governments greater autonomy in environmental governance. Local officials, in their unilateral pursuit of economic growth and job promotion, choose to loosen environmental regulations and engage in "bottom-up competition", or even divert environmental expenditures to the development of local economies, resulting in "free-riding" phenomenon in exchange for economic growth and environmental governance by sacrificing environmental resources, which ultimately lead to environmental pollution or increase carbon emissions (Gray et al. 2004; Kunce et al. 2007; Dijkstra et al. 2010). while centralized environmental management would enable central governments to provide better environmental public services, thereby avoiding the "free-riding" of local governments and the insufficient supply of environmental public goods resulting from decentralization. (2) Under a 
decentralized environmental management system, local governments, in order to obtain sufficient economic benefits, may form political collusion with local enterprises, or even cooperate with enterprises to conceal the facts of environmental pollution, leading to inefficient environmental policies and thus aggravating environmental pollution (Burgess et al. 2012; Long et al. 2014). (3) Environmental public services usually have economy scale, and the provision of environmental public services by the central government may reduce supply costs (Liu et al. 2015), plus the spillover effect of environmental public goods also determines that socially optimal provision and environmental governance by local governments are unlikely to be achieved (due to a lack of cooperation from local governments). On the contrary, facilitation theory scholars (decentralization supporters) argue that environmental decentralization helps local governments to target and implement environmental regulations that are more responsive to local needs and interests, which is conducive to controlling environmental pollution and improving environmental standards (Fslleth et al. 2009; Tan et al. 2015). From the perspective of fiscal decentralization and haze management, Li and Han (2015) have confirmed that decentralization has a favorable effect on environmental quality improvement. The reason for this is that, first of all, the regional heterogeneity in environmental pollution and demand for environmental public goods gives local governments a greater information advantage (local governments are closer to the public and have a better understanding of the real state of the environment and the environmental preferences of residents in their jurisdictions) than the central government in the provision of public goods, thus enabling local governments to provide better environmental governance services to residents in an efficient and low-cost manner (Zou et al. 2019; Lu et al. 2019; Banzhaf et al. 2012). If environmental centralization is adopted, heterogeneity between regions will be ignored and public services provided by the central government will struggle to meet real local needs. Secondly, the lack of clarity of responsibility for environmental governance is the root cause of the ineffective implementation of environmental policies (Lopez et al. 2000). The decentralization of environmental power, on the one hand, makes the responsibility of local governments in environmental management matters more clear and governmental behavior more transparent, and on the other hand, helps to mobilize residents to exercise environmental supervision power, thus helping to promote the transformation and upgrading of industrial structure and ultimately improve environmental quality (Li 2018; Goel et al. 2017). Oates and Schwab (Oates et al. 1988), representatives of uncertainty theory, argue that in the context of jurisdictional competition for resource mobility, local governments seek to maximize self-interest rather than social welfare. Therefore, the environmental impact of decentralization can be either negative or positive, or even insignificant (He 2015). Fredriksson and Wollscheid's (2014) study found that different forms of environmental decentralization have different impacts. Environmental administrative decentralization usually has a positive drive on the local environment, while environmental monitoring decentralization has a negative effect on the local environment. Similarly, Ferrara (2014) supports the uncertainty theory, arguing that environmental decentralization can result in both "bottom-up 
competition" and "top-up competition", with the direction of influence depending on the extent of transboundary pollution of public goods (e.g. $\mathrm{CO}_{2}$ ) and the heterogeneity of preferences among local governments (Besley et al. 2003). He's (2015) study found that fiscal decentralization has no significant effect on the "three wastes" of industry. Some scholars have also confirmed that decentralization has a significant nonlinear effect on environmental pollution. For example, Peng (2016) and Qi (2014) showed that there is a significant inverted U-shaped relationship between environmental decentralization and industrial green transition or environmental pollution, and this inverted $U$-shaped relationship depends on three factors, such as per capita income, foreign direct investment and industrial structure (Li et al. 2016).

In recent years, with the increasing prominent environmental problems in China, carbon emissions have gradually become an important factor plaguing socio-economic development, and more and more scholars have begun to focus on the impact of Chinese decentralization on carbon emissions. Existing studies have shown that in addition to the impact of decentralization on the growth of carbon emissions presents an inverted U-shaped relationship (Zhang et al. 2017; Halkos et al. 2013), most of the findings are consistent with the first view above, which suggests that decentralization will increase the level of carbon emissions in the region and the surrounding areas, thus making it more difficult to reduce carbon emissions (Zhang et al. 2011; Lu and Zhang 2016; Zhang et al. 2017; Ran et al. 2020; Xiao et al. 2014; Tian et al. 2018). Furthermore, most scholars attribute this result to the incentive distortions and inadequate constraints caused by Chinese-style decentralization reforms, that is, local governments and officials are more willing to loosen environmental standards to attract foreign investment in exchange for economic growth and job promotion, while the carbon emissions, as public goods with significant spillovers, are often ignored by local governments, resulting in higher carbon emissions and affecting the quality of local and neighboring environments.

In summary, existing studies are divided on the environmental effects of decentralization. Although existing studies conclude that decentralized management increases environmental pollution, this result is still debatable. There are four main reasons: First, on the index depiction of the connotation of environmental decentralization in China, a relatively unified understanding and accurate representation has not yet been formed. Existing studies mainly adopt indirect methods to characterize environmental decentralization, in other words, judging whether the state is decentralized or centralized based on the legal system and factual characteristics, or using fiscal decentralization indicators to approximate environmental decentralization, and then analyzing the environmental decentralization behavior of local governments and its impact on the environment (Jacobsen et al. 2012; Deng et al. 2012). In fact, environmental decentralization is an environmental management institution established by the central government through the delegation of environmental protection functions to different government levels, reflecting the division of environmental powers with basic environmental public services at the core, and is a dynamic process of evolution and interaction. However, fiscal decentralization emphasizes an incentive mechanism that 
combines "political centralization and economic decentralization", which hardly reflects the division of responsibility for environmental protection between the central government and local governments. Therefore, the relative independence and uniqueness of environmental protection determine that fiscal decentralization cannot replace environmental decentralization, and if fiscal decentralization is used to approximate the environmental decentralization of local governments, it will lead to deviations in the measurement of environmental decentralization, thus affecting the investigation of the real relationship between environmental decentralization and environmental pollution. Second, in exploring the environmental (carbon emission) effects of decentralization, most existing studies assume that provinces and regions are independent of each other, that is to say, carbon emissions do not affect each other and ignore the spatially correlated effects of environmental pollution between regions, while spatial spillover effects of environmental pollution (carbon emissions) have become a common problem in many federal countries as well as in developing countries. It also ignores the possible impact of spatial heterogeneity in the level of environmental decentralization on regional estimation results, making it difficult for environmental federalism, which is rooted in the theory of fiscal decentralization, to comprehensively explain the underlying mechanisms of local pollutant changes from the perspective of environmental decentralized management. Third, previous studies have not considered the interaction between environmental and fiscal decentralization when analyzing the effects of environmental decentralization on environmental pollution. In fact, in the context of fiscal decentralization reform and environmental protection "compartmentalization", fiscal decentralization gives local governments greater economic autonomy, but also to a certain extent affects the implementation of local environmental management power. Therefore, in order to more accurately investigate the impact of environmental decentralization on local carbon emissions, it is necessary to focus on the synergy between environmental decentralization and fiscal decentralization on carbon emissions under the circumstance of Chinese-style decentralization. Fourthly, there is little literature on the relationship between environmental decentralization and carbon emissions, with relevant studies mainly focusing on the impact of fiscal decentralization on environmental pollution, and the pollutants involved are mainly industrial "three wastes", sulfur dioxide and smog (Bai et al. 2017; Xue et al. 2012; Qi et al. 2014), while the influence mechanism of decentralization on different environmental pollutants are different. Compared with previous research, this study may make three contributions: (1) From the perspective of the environmental management institution, it constructed decentralized indicators that fit the actual functions of environmental protection, discussed the impact of different types of environmental decentralization on carbon emissions and their effect mechanisms, and provided a basis for improving the division of environmental responsibilities in China. (2) Based on the spatial perspective, the spatial dynamic panel model between environmental decentralization and carbon emissions was constructed, which expands the research thinking in the field of environmental decentralization and carbon emissions, and enriches the connotation of Chinese-style environmental 
federalism theory. (3) From the regional level, the study analyzed the differences of the impact of environmental decentralization on carbon emissions, and the direction and degree of the interaction effect of environmental decentralization and fiscal decentralization on carbon emissions under the background of fiscal decentralization at the regional level, so as to provide a policy reference for the formulation of differentiated environmental decentralization strategies to reduce emissions.

Model and methodologies

\section{Model building}

In order to empirically investigate the impact of Chinese-style environmental decentralization and other socio-economic factors on carbon emissions, this study built a benchmark model to investigate the impact of environmental decentralization on carbon emissions in China, based on the models of the relationship between decentralization and environmental pollution by He (2015), and Ran (2020), as follows.

$$
\ln P C O_{2 i t}=\beta_{0}+\beta_{1} E D_{i t}+\beta_{2} F D_{i t}+\sum \alpha_{j} X_{i j t}+\varepsilon_{i t}
$$

where $i$ denotes the province, $i=1,2, \cdots, 30 ; t$ represents time; $\ln P C O_{2 i t}$ is the explained variable, expressed as the logarithm of the provincial per capita carbon emissions; $E D_{i t}$ and $F D_{\text {it }}$ are the core explanatory variables, respectively representing the level of environmental decentralization and fiscal decentralization in each province (municipality directly under the central government, autonomous region, hereinafter collectively referred to as provinces). $X_{i j t}$ indicates other control variables affecting carbon emissions, including the level of economic development $\left(\ln P G D P_{i t}\right)$ and its squared term $\left(\ln P G D P_{i t}\right)^{2}$, population size $\left(\ln P D_{i t}\right), \mathrm{R} \& \mathrm{D}$ intensity $\left(R D_{i t}\right)$, foreign direct investment $\left(F D I_{i t}\right)$, industrial structure $\left(I N D U S_{i t}\right)$ and trade openness $\left(O P E N_{i t}\right) . \varepsilon_{i t}$ is random error and is assumed to follow a normal distribution. $\beta$ and $\alpha_{j}$ are model estimation coefficients.

Given the potential endogeneity of the model itself and the time lag effect of the explained variables, this article incorporated a lagged phase one of the explained variables into the model and set up a dynamic panel model to tackle the risk of estimation bias due to omitted variables and the potential endogeneity of the model, so as to fully investigate the impact of factors other than the explained variables on carbon emissions in the model. At the same time, considering the path-dependence (spatial correlation) problem caused by carbon emission externalities and spillover effects (Liu et al. 2018), the impact of carbon emissions, we included the spatial lag term $W \times \ln P C O_{2 i t}$ as an explanatory variable in the regression model to examine how the level of carbon emissions in a certain region is affected by the carbon emissions of the neighboring provinces. Based on the above analysis, the original benchmark model was extended to a dynamic spatial panel data model, that is

$$
\ln P C O_{2 i t}=\beta_{0}+\tau L \cdot \ln P C O_{2 i t}+\rho W \times \ln P C O_{2 i t}+\beta_{1} E D_{i t}+\beta_{2} F D_{i t}+\sum \alpha_{j} X_{i j t}+\delta_{i}+\mu_{t}+\varepsilon_{i t}
$$

In the formula, $\tau$ is a time lag coefficient indicating the effect of the previous period carbon emission level on the current period; $\rho$ is the spatial hysteresis coefficient, which reflects the extent to which carbon emissions from neighboring provinces affect carbon emissions in the region; $W$ is a geospatial adjacency weights matrix, the value of which is determined according to the Queen's principle of geographic proximity, that is, the weight $\left(w_{i j}\right)$ is set at 1 when two regions are adjacent and share a common border and vertex, and 0 otherwise (Hainan Province is assumed to be adjacent to Guangdong Province, given its closest geographical location and strong economic ties with that province, although it is not geographically 
remaining variables are interpreted in the same way as in Eq. (1).

In addition, to test the joint effect of environmental and fiscal decentralization on carbon emissions, the empirical model included an interaction term for environmental and fiscal decentralization to reflect the synergistic effect of environmental and fiscal resource allocation on carbon emissions. The model with an interaction term for the variables is:

$$
\begin{gathered}
\ln P C O_{2 i t}=\beta_{0}+\tau L \cdot \ln P C O_{2 i t}+\rho W \ln P C O_{2 i t}+\beta_{1} E D_{i t}+\beta_{2} F D_{i t}+\sum \alpha_{j} X_{i j t}+\beta_{3} E D_{i t} \times F D_{i t}+ \\
\delta_{i}+\mu_{t}+\varepsilon_{i t}
\end{gathered}
$$

\section{Variable measurement}

In this paper, we used 30 provinces in mainland China (Considering the availability and completeness of data, Hong Kong, Macau, Taiwan and Tibet were not involved in this study) in 2003-2017 as the study sample and referred to the research results on carbon emissions both at home and abroad, and selected eight major factors affecting carbon emissions as the independent variables for empirical analysis. The definition and measurement of each variable are as follows.

\section{Explained variable}

For the explained variables, carbon emissions per capita for each province in China are used here. Since the purpose of the study is to explore the impact of environmental decentralization on carbon emissions, it is important to estimate carbon emissions accurately. This paper referred to the reference method provided by the Intergovernmental Panel on Climate Change (IPCC) of the United Nations, and estimated the per capita carbon emissions in each province based on the consumption of eight major fossil energy sources (raw coal, coke, crude oil, gasoline, kerosene, diesel oil, fuel oil, and natural gas). The formula is as follows.

$$
P C O_{2 i t}=\left(\sum_{j=1}^{8} E_{j} \times S C C_{j} \times C E C_{j} \times 44 / 12\right) / P O P_{i t}
$$

In the formula, $i$ and $t$ respectively stand for province and year, $j$ stands for energy type, $E$ stands for fossil energy consumption, SCC stands for standard coal conversion factor for fossil energy, CEC stands for carbon emission coefficient for fossil energy, 44/12 stands for the ratio of molecular weight of $\mathrm{CO}_{2}$ to molecular weight of carbon, $P O P$ is the population at the end of the year, and other variables or letters have the same meaning as in equation (1). The energy standard coal conversion coefficient and carbon emission coefficient used to calculate carbon emissions are from the Guidelines for National Greenhouse Gas Emissions Inventories, as shown in table 1.

Table 1 The conversion coefficient of standard coal and carbon emission coefficient for eight fossil energy sources

\begin{tabular}{ccccccccc}
\hline Coefficient & Raw coal & Coke & Crude oil & Gasoline & Kerosene & Diesel oil & Fuel oil & Natural gas \\
\hline SCC $(\mathrm{kg} \mathrm{tce} / \mathrm{kg})$ & 0.7143 & 0.9714 & 1.4286 & 1.4714 & 1.4714 & 1.4571 & 1.4286 & $1.3300^{*}$ \\
$\mathrm{CEC}(\mathrm{kg} / \mathrm{kg} \mathrm{tce})$ & 0.7559 & 0.8550 & 0.5857 & 0.5538 & 0.5714 & 0.5921 & 0.6185 & 0.4483 \\
\hline
\end{tabular}

Note: the unit of conversion coefficient of natural gas is $\mathrm{kg}$ standard coal $\cdot \mathrm{m}^{-3}$.

\section{Core explanatory variables}

Environmental decentralization and fiscal decentralization are the core explanatory variables in this paper, and thus it is extremely important to correctly understand their connotations and accurately measure the indicators. The environmental decentralization involved here refers to the central government's delegation of environmental management and powers to local governments, and gives local governments a certain degree of autonomy in environmental governance, which regulates the division of environmental protection powers and governance responsibilities between the central and local governments through decentralization. The aim is to achieve compatibility of incentives between central and local environmental 
management and effective provision of public services for environmental protection through gradual adjustment and optimization of environmental powers between governments. Unlike western environmental federalism, Chinese environmental decentralization is holistic in nature, and gives greater freedom to local governments to delegate environmental management. In addition, China has a relatively detailed division of environmental powers, including environmental policymaking, environmental monitoring, environmental supervision, investment in environmental facilities and environmental information services (Qi et al. 2014). Due to the difficulty of constructing a comprehensive measure of environmental decentralization that is self-consistent between practice and theory, previous studies have mostly measured environmental decentralization using fiscal decentralization indicators through an indirect approach. However, the special nature of environmental management power means that fiscal decentralization cannot and will not replace environmental decentralization. Only by directly constructing indicators for measuring environmental decentralization based on the internal logic of environmental decentralization can we objectively and accurately reflect the content of environmental decentralization in China. Considering the essential connotation of environmental decentralization, this paper used the distribution of personnel in environmental protection agencies at different levels of government to portray the overall Chinese environmental decentralization $\left(E D_{i t}\right)$, which was subdivided into three types of environmental administrative decentralization $\left(E A D_{i t}\right)$, environmental supervision decentralization $\left(E S D_{i t}\right)$ and environmental monitoring decentralization $\left(E M D_{i t}\right)$. The distribution of personnel in environmental protection departments at different levels of government is used to measure the degree of decentralization of the environmental management institution for the following four reasons: (1) the personnel of environmental protection agencies, as executors for exercising environmental protection powers, can reflect the specific division of environmental powers among different levels of government to a certain extent; (2) The change in the distribution of personnel in environmental protection agencies can reflect the change in the environmental management system with the division of environmental responsibility as the core. (3) The essence of environmental decentralization is management decentralization, and the distribution of personnel better reflects the essence of environmental decentralization. (4) The use of personnel distribution to measure decentralization is also a common international practice. Therefore, the ratio between the number of local and national personnel per capita in environmental protection agencies is of strong scientific validity and applicability to characterize the level of environmental decentralization in China. This article discusses the impact of environmental decentralization on carbon emissions in terms of the overall effect, environmental administrative power, environmental monitoring power and environmental supervision power. The specific formulas for calculating each type of environmental decentralization are as follows.

where $\mathrm{i}$ and t denote province and year respectively; $S Y S_{i t}, S Y S A_{i t}, S Y S M_{i t}$ and $S Y S S_{i t}$ represent the number of personnel in the environmental protection system, the number of environmental protection administrative personnel, the number of environmental protection monitoring personnel and the number of environmental protection supervising personnel respectively. $S Y S_{t}, S Y S A_{t}, S Y S M_{t}$ and $S Y S S_{t}$ are 
respectively the number of personnel in the environmental protection system, the number of environmental protection administrative personnel, the number of environmental protection monitoring personnel and the number of environmental protection supervising personnel at the national (including central and local) level. $P O P_{i t}$ and $P O P_{t}$ respectively indicate the size of the population of each province and in the country as a whole, both expressed in terms of population at the end of the year. GDP $i t$ is the GDP of each province, $G D P_{t}$ is the national GDP, and $\left[1-\left(G D P_{i t} / G D P_{t}\right)\right]$ is an economic size reduction factor used to deflate the impact of economic size on the actual degree of environmental decentralization (the higher the degree of economic development, the more local environmentalists are set up) to reduce possible endogenous risks. The greater the value of $E D_{i t}$ above, the higher the degree of environmental weighting, and other weighting values (e.g., $E A D_{i t}, E S D_{i t}$, and $E M D_{i t}$ ) have a similar relationship.

Since fiscal decentralization is the basis of environmental decentralization and there is interaction between the two, fiscal decentralization is also taken as the core explanatory variable affecting carbon emissions. Based on the availability of data, this paper adopted the fiscal autonomy index to characterize the fiscal decentralization of each province with reference to the research method of Zou (2019) to compensate for the inability of the existing index to reflect the differences in the degree of fiscal decentralization among local governments. The specific formula is $F D_{i t}=F E_{i t} / F I_{i t}$, in which $F D_{i t}$ indicates the degree of fiscal decentralization in local governments, and $F E_{i t}$ and $F I_{i t}$ are the fiscal expenditures in the provincial budgets and fiscal revenues in the regional budgets respectively.

\section{Control variables}

There are many factors influencing carbon emissions, and for robustness reasons, this study also selected other factors affecting carbon emissions as control variables for the model. (1) The level of economic development $\left(\ln P G D P_{i t}\right)$ is measured by the logarithm of the per capita gross domestic product $(P G D P)$ in each province, and the GDP deflator is used to eliminate the impact of price fluctuations; the squared term of the level of economic development $\left(\ln P G D P_{i t}\right)^{2}$ is also introduced to examine the existence of a Kuznets curve for carbon emissions. (2) Population size $\left(\ln P D_{i t}\right)$ is expressed as the logarithm of the ratio of the end-of-year population to the area of administrative divisions in each province. (3) $\mathrm{R} \& \mathrm{D}$ intensity $\left(R D_{i t}\right)$ is measured as the share of GDP spent on R\&D in each province. (4) Foreign Direct Investment $\left(F D I_{i t}\right)$ is expressed by the proportion of the actual foreign direct investment (converted by the average exchange rate of RMB against the US dollar) in each province to GDP. (5) The industrial structure $\left(\operatorname{lnINDUS} S_{i t}\right)$ is measured using the value-added of the secondary sector as a share of GDP. (6) Trade openness $\left(O P E N_{i t}\right)$ choose a measure of the total import and export trade in each province as a share of GDP.

\section{Data sources and variable descriptive statistics}

The raw data used to estimate provincial carbon emissions, environmental decentralization (including environmental system decentralization, environmental administration decentralization, environmental supervision decentralization and environmental monitoring decentralization), fiscal decentralization, economic development, population size and research and development intensity were taken from successive China Energy Statistical Yearbooks, China Environment Yearbook, China Finance Yearbook, China Statistical Yearbook and China Science and Technology Statistical Yearbook. As the data on the personnel of environmental protection agencies at all levels compiled by the China Environmental Yearbook ended in 2015, the number of environmental protection system personnel, environmental protection administrative personnel, environmental protection monitoring personnel and environmental supervision personnel in each province in 2016-2017 was calculated from the sub-data in the China 
Environmental Yearbook, and the missing numbers of environmental protection system personnel and environmental protection administrative personnel in individual provinces were made up by consulting the statistical yearbooks and statistical bulletins of the corresponding provinces. Data on the output value of secondary industries needed to measure the industrial structure, the total import and export volume needed to open up trade, and FDI come from the statistical yearbooks of each province (Hebei' s and Gansu's FDI were respectively taken from the Hebei Economic Yearbook and Gansu Development Yearbook). All indicators in the text expressed in monetary units were deflated using the 2000 price index as the base period (FDI data were first converted using the average exchange rate of the RMB against the USD for each year and then deflated using the 2000 price index). The definitions of the variables and the results of their descriptive statistics are shown in table 2. Table 2 shows that, except for the large standard deviation of the squared term of the logarithm of GDP per capita, the standard deviations of the other variables are generally small, indicating that the selected sample is stable overall. However, there is obvious heterogeneity among the provinces for each variable, taking the core explanatory variable environmental decentralization as an example, the maximum value of environmental decentralization is 2.347 and the minimum value of environmental decentralization is 0.059 , the former is 39.8 times of the latter; similarly, environmental administrative decentralization, environmental monitoring decentralization and environmental supervision decentralization also show similar difference characteristics.

Table 2 Definitions and descriptive statistics of all variables (2003-2017)

\begin{tabular}{|c|c|c|c|c|c|c|}
\hline $\begin{array}{c}\text { Variable } \\
\text { name }\end{array}$ & Variable definition & Mean & Std. D & Max. & Min. & Obs. \\
\hline $\ln \mathrm{PCO}_{2}$ & Logarithm of per capita carbon emissions & 1.711 & 0.551 & 3.516 & 0.269 & 450 \\
\hline L. $\ln \mathrm{PCO}_{2}$ & Logarithm of per capita carbon emissions lagging by one period & 1.661 & 0.546 & 3.289 & 0.138 & 450 \\
\hline$E D$ & Environmental decentralization & 1.008 & 0.365 & 2.347 & 0.059 & 450 \\
\hline$E A D$ & Decentralization of environmental administration & 1.027 & 0.582 & 10.612 & 0.186 & 450 \\
\hline$E M D$ & Decentralization of environmental monitoring & 1.033 & 0.725 & 14.203 & 0.069 & 450 \\
\hline$E S D$ & Decentralization of environmental supervision & 0.972 & 0.545 & 3.503 & 0.185 & 450 \\
\hline$F D$ & Fiscal decentralization & 2.248 & 0.980 & 7.426 & 0.197 & 450 \\
\hline $\ln P G D P$ & Logarithm of GDP per capita & 3.031 & 0.650 & 4.586 & 1.246 & 450 \\
\hline$(\ln P G D P)^{2}$ & Square of per capita GDP logarithm & 9.607 & 3.9705 & 21.031 & 1.551 & 450 \\
\hline $\ln P D$ & Logarithm of population density & 5.429 & 1.266 & 8.249 & 2.036 & 450 \\
\hline$R D$ & Proportion of R \& D expenditure in GDP & 1.871 & 1.535 & 9.844 & 0.172 & 450 \\
\hline$F D I$ & Proportion of foreign direct investment in GDP & 3.197 & 2.376 & 10.941 & 0.054 & 450 \\
\hline $\operatorname{lnINDUS}$ & Logarithm of the proportion of industrial production in GDP & 3.812 & 0.207 & 2.944 & 4.202 & 450 \\
\hline OPEN & Proportion of total export-import volume in GDP & 0.394 & 0.424 & 1.891 & 0.018 & 450 \\
\hline
\end{tabular}

\section{Results and discussions}

\section{Spatial correlation test for carbon emissions}

Testing the existence of spatial correlation of variables is a prerequisite for the empirical analysis of the effect of environmental decentralization on the spatial impact of carbon emissions using dynamic spatial panel models. At present, most scholars adopt Moran's I index to characterize the spatial autocorrelation of regional variables (the correlation between a certain geographical phenomenon in one spatial unit and that in the neighboring spatial unit), which is calculated as follows. 
$448=\left[\sum_{i=1}^{n} \sum_{j=1}^{n} w_{i j}\left(Y_{i}-\bar{Y}\right)\left(Y_{i}-\bar{Y}\right)\right] /\left(S^{2} \sum_{i=1}^{n} \sum_{j=1}^{n} w_{i j}\right)$

449 in the formula, $S^{2}=\frac{1}{\mathrm{n}} \sum_{i=1}^{n}\left(Y_{i}-\bar{Y}\right), \bar{Y}=\frac{1}{\mathrm{n}} \sum_{i=1}^{n} Y_{i}, Y_{i}$ is the observed value for province i (i.e. carbon

450 emissions per capita); $n$ is the number of provinces. $w_{i j}$ is the spatial weight of inter-provincial neighbors

451 (considering that the Queen spatial weight matrix better reflects the real spatial relationship than the Rook

452 spatial weight matrix, this paper adopted the Queen proximity principle to construct the spatial weight

453 matrix to test the spatial correlation of carbon emissions). Moran index $I$ indicates the global spatial

454 autocorrelation of provincial per capita carbon emissions in China, and its value range is $-1 \leqslant I \leqslant 1$. When $I$

455 is close to -1 , it means that per capita carbon emissions are spatially negatively correlated among provinces;

456 when $I$ is close to 1 , it means that per capita carbon emissions are spatially positively correlated; and when

$457 I$ is equal to 0 , it means that there is no spatial autocorrelation of carbon emissions. Table 3 shows the

458 global Moran's $I$ index of carbon emissions per capita for provincial areas in China from 2003 to 2017

459 obtained using GeoDa1.10 software processing.

460 Table 3 Global Moran's I of China's provincial carbon emissions per capita from 2003 to 2017

\begin{tabular}{llllll}
\hline Year & Moran's $I$ & $\mathrm{E}(I)$ & $\mathrm{SD}(I)$ & $\mathrm{Z}(I)$-value & $P$-value \\
\hline 2003 & 0.2398 & -0.0357 & 0.1173 & 2.5023 & 0.02 \\
2004 & 0.3680 & -0.0357 & 0.1280 & 3.2772 & 0.01 \\
2005 & 0.3340 & -0.0357 & 0.1223 & 3.1516 & 0.01 \\
2006 & 0.3450 & -0.0357 & 0.1175 & 3.3837 & 0.01 \\
2007 & 0.3359 & -0.0357 & 0.1114 & 3.4869 & 0.01 \\
2008 & 0.3148 & -0.0357 & 0.1015 & 3.5903 & 0.01 \\
2009 & 0.2853 & -0.0357 & 0.0989 & 3.3854 & 0.02 \\
2010 & 0.3186 & -0.0357 & 0.0969 & 3.7912 & 0.01 \\
2011 & 0.2836 & -0.0357 & 0.0911 & 3.6169 & 0.01 \\
2012 & 0.2874 & -0.0357 & 0.0935 & 3.5556 & 0.01 \\
2013 & 0.2906 & -0.0357 & 0.0985 & 3.4022 & 0.01 \\
2014 & 0.2930 & -0.0357 & 0.1004 & 3.3597 & 0.01 \\
2015 & 0.2840 & -0.0357 & 0.1012 & 3.2446 & 0.02 \\
2016 & 0.2786 & -0.0357 & 0.1020 & 3.1502 & 0.03
\end{tabular}

Note: $\mathrm{E}(I)$ is the expected value, $\mathrm{E}(I)=-1 /(\mathrm{n}-1) ; \mathrm{SD}(I)$ is the standard deviation; $\mathrm{Z}(I)$ is the standardized statistic, $\mathrm{Z}(I)=[I-E(I)] / \sqrt{\operatorname{var}(I)} ; P$ is the level of significance of $I$, obtained by Monte Carlo simulation 1000 times. In this study, if the $P$-value is less than the given significance level $(\alpha=0.05)$ and $|\mathrm{Z}|>1.96$, it means that the provincial per capita carbon emissions have significant spatial correlation; otherwise, the spatial correlation is not significant; when the $Z$-value is 0 , it means that the provincial per capita carbon emissions are randomly distributed.

From Table 3, it can be seen that the global Moran's I index of carbon emissions per capita in China's provinces all passed the 5\% level of significance test, with Z-values above 2.5 (>1.96) and Moran's I values 
around 0.3, which indicates that carbon emissions per capita in China's provinces are not completely random, but show a significant positive spatial correlation. Although Moran's I index shows a gradual downward trend over time, provinces with similar per capita carbon emissions over the study period still show a clear clustering and strong spatial dependence (Table 3). In order to further explore the similar clustering characteristics of provincial carbon emissions per capita in local space, this paper adopted the local Moran scatter plot and LISA (Local Indicators of Spatial Association) clustering plot to analyze the clustering among provincial carbon emissions per capita and its significance. Figure 1 shows the local Moran scatter plot of China's provincial carbon emissions per capita based on the Queen's spatial adjacency matrix. In Figure 1, the quadrant I indicates that areas with high per capita carbon emissions are surrounded by areas with high per capita carbon emissions, referred to as "High-High" (H-H) agglomeration areas; quadrant II indicates that areas with low per capita carbon emissions are surrounded by areas with high per capita carbon emissions, i.e. "Low-High" (L-H) agglomeration areas; quadrant III indicates areas with low per capita carbon emissions and low per capita carbon emissions in the surrounding area, that is, "LowLow" (L-L) agglomeration areas; Quadrant IV indicates that areas with high per capita carbon emissions are surrounded by areas with low per capita carbon emissions, known as " High-Low" (H-L) agglomeration areas. The H-H and L-L clusters represent the positive spatial correlation of carbon emissions per capita at the provincial level, while the $\mathrm{L}-\mathrm{H}$ and $\mathrm{H}-\mathrm{L}$ clusters represent the strong negative spatial correlation of carbon emissions per capita at the provincial level. 

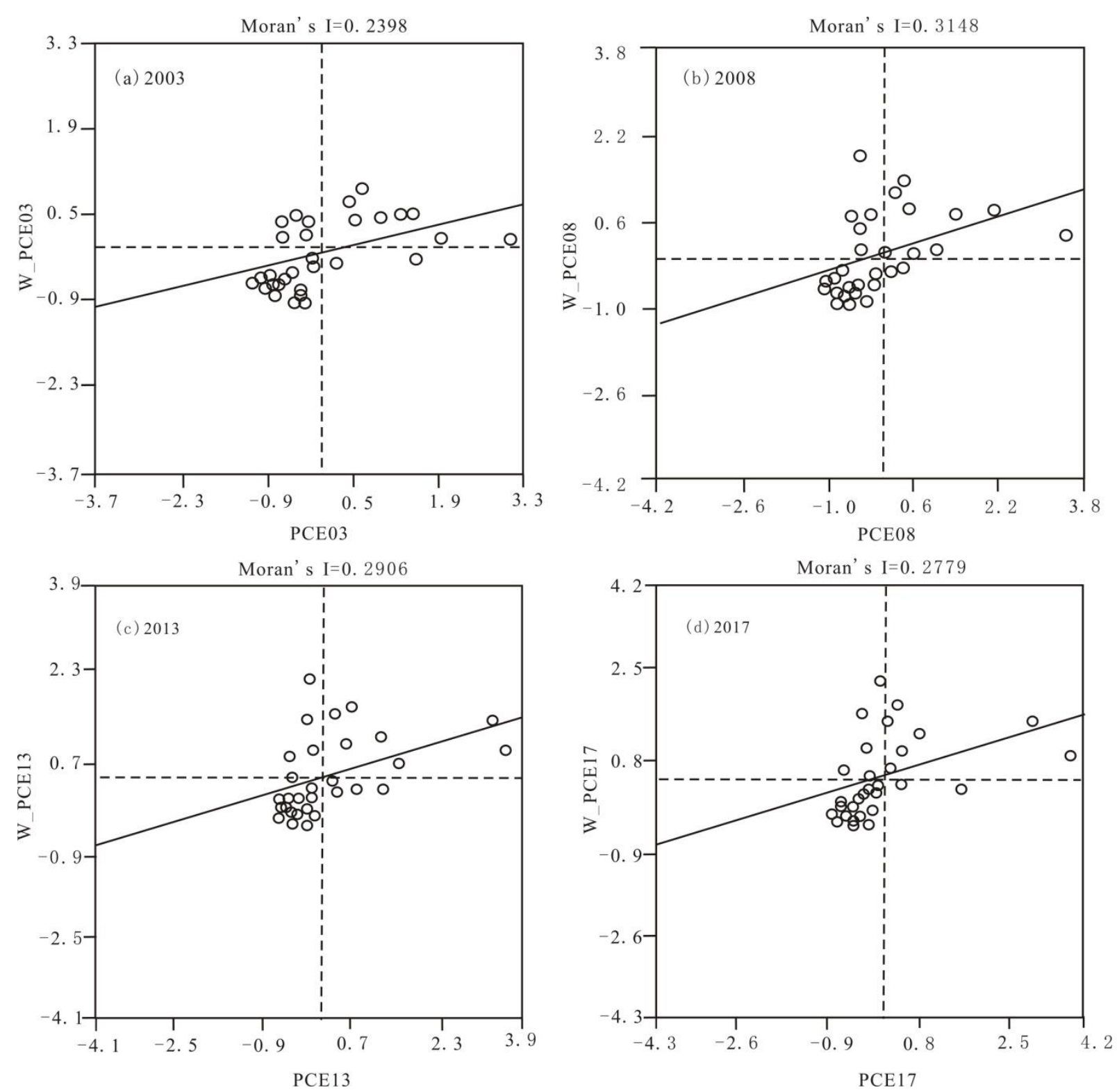

Fig. 1 Moran scatter plot of China's provincial carbon emission per capita in typical years (2003, 2008, 2013 and 2017)

Figure 1 shows that the majority of Chinese provinces are located in quadrants I and III. The proportion of provinces in quadrants I $(\mathrm{H}-\mathrm{H})$ and III $(\mathrm{L}-\mathrm{L})$ reached $70.0 \%, 73.3 \%, 70.0 \%$ and $76.7 \%$ in 2003, 2008, 2013 and 2017 respectively, while the corresponding percentages of provinces in quadrants II (L-H) and IV (H-L) were only $30.0 \%, 26.7 \%, 30.0 \%$, and $23.3 \%$ respectively. This indicates that the per capita carbon emissions of most Chinese provinces have a strong spatial correlation on a local scale during the study period, especially the spatial clustering features of H-H and L-L are very obvious, which shows that there is a strong spatial synergy (or positive correlation), in other words, an increase or decrease in the per capita carbon emissions of the surrounding provinces will lead to an increase or decrease in the per capita carbon emissions of the region. 

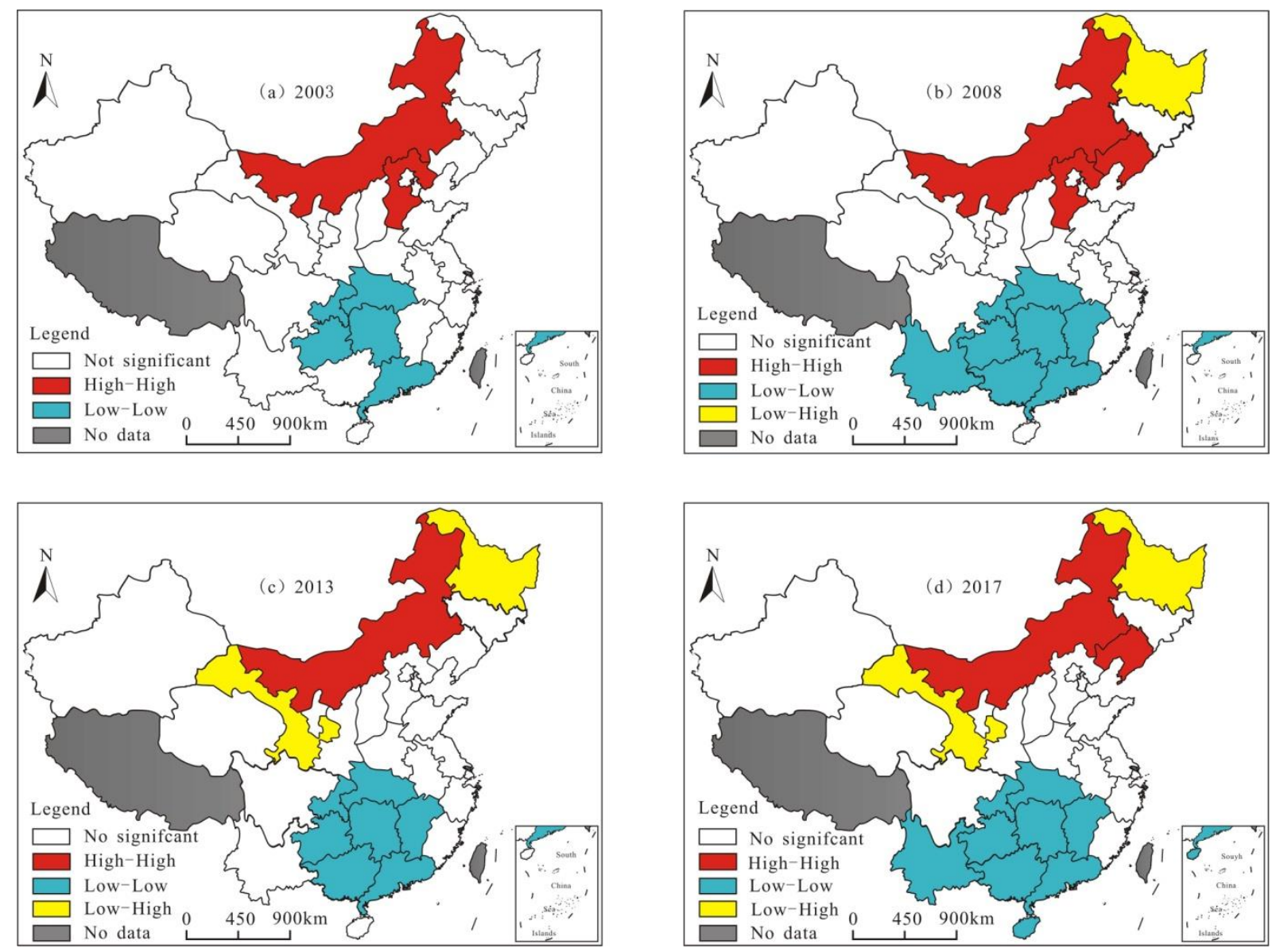

Fig. 2 LISA cluster map of China's provincial carbon emission per capita in typical years (2003, 2008, 2013 and 2017)

In order to better reflect the spatial clustering of carbon emissions and its significance, this paper plotted the Moran's I scatter plots for the above four years directly on the map of China, and then obtains the LISA clustering map of provincial carbon emissions per capita in China. Figure 2 shows that the spatial pattern of provincial per capita carbon emissions in China has remained relatively stable over the period 2003-2017. In addition to the increasing trend of provinces with significant L-L and L-H agglomerations, the number of provinces with significant $\mathrm{H}-\mathrm{H}$ agglomerations did not change significantly, especially the number of provinces with H-L agglomerations (higher per capita carbon emissions than the surrounding provinces) did not pass the significance test throughout the study period, which indicates the likelihood of a significant "bump" in per capita carbon emissions nationwide is extremely low. Nevertheless, there are certain differences in the spatial clustering pattern of carbon emissions per capita in China's provinces and regions in different years. In 2008, for example, the spatial clustering of provincial carbon emissions per capita in Chinais very obvious as shown in Figure 2(b). H-H clustering was mainly located in the coastal area and yellow economic belt in northern China, but the only provinces that passed the significance test are Inner Mongolia, Hebei and Liaoning. The reason is that these provinces are important energy production and heavy industry bases in China, with a high proportion of energy development and consumption, and the high energy consumption and high emission industries represented by coal, 
515

516

517

518

519

520

521

522

523

524

525

526

527

528

529

530

531

532

533

534

535

536

537

538

539

540

541

542

543

544

545

546

547

548

549

petrochemicals, iron and steel, and metallurgy have produced a large amount of carbon emissions to the local environment. In particular, in recent years, Inner Mongolia has been increasingly developing its coal resources, while at the same time undertaking a large number of backward production capacity elimination from developed areas, coupled with the slow population growth in the region, which has pushed up per capita carbon emissions and has always shown high-value clustering characteristics in the study period (Figure 2). In 2008, the clustering of L-L provincial per capita carbon emissions in China was mainly concentrated in the middle reaches of the Yangtze River, southwest China and south China, with significant spatial correlation in Hubei, Hunan, Jiangxi, Yunnan, Chongqing, Guizhou, Guangxi and Guangdong (Figure 2b). However, the reasons for the low per capita carbon emission clustering pattern in these provinces are different. The decrease in per capita carbon emissions in Hunan, Hubei and Jiangxi provinces is due to the implementation of the central rise strategy in 2006, which accelerated the structural transformation of traditional industries in these provinces, while the impact of technological advances contributed to a reduction in their total carbon emissions, which in turn led to a decrease in per capita carbon emissions; while in Yunnan, Guizhou and Guangxi, were affected by the financial crisis in 2008, which slowed down their economic growth, resulting in a smaller increase in the demand for energy from economic activities, which led to a decrease in their per capita carbon emissions. The decrease in per capita carbon emissions in Chongqing and Guangdong is mainly due to the gradual shift of their traditional energy-intensive industries to the inland northwest and the gradual development of capital-intensive and knowledge innovation-driven high-tech industries in the original regions, which has reduced their reliance on primary energy and improved their energy efficiency. The influx eventually led to a decline in per capita carbon emissions. As for the provinces with significant L-H agglomerations in 2008 (with relatively lower per capita carbon emissions than the surrounding provinces), the presence of Heilongjiang in the northeast may be related to the reduction of its total carbon emissions due to the accelerated transformation of its heavy industry structure and the elimination of a number of backward production capacity by the northeast revitalization policy. The above analysis suggests that it is necessary to consider the spatial spillover effect of carbon emissions in the panel model when exploring the impact of environmental decentralization on carbon emissions.

\section{Empirical analysis of the impact of environmental decentralization on carbon emissions}

\section{The impact of environmental decentralization on carbon emissions at the national level}

Based on the aforementioned models and relevant data, this paper explored the impact of environmental decentralization on carbon emissions by double-fixed individual and time effects using Stata 14.0 software. The final estimation results for each model are presented in Table 4. In particular, models 5 and 6 are respectively the results of dynamic spatial panel regression estimates with environmental decentralization and fiscal decentralization as core explanatory variables and adding geospatial adjacency weight matrices. For robustness reasons, Table 4 also presents the estimated results of ordinary least 
squares (OLS) and static spatial panel regressions.

The estimated effects of environmental decentralization and fiscal decentralization on provincial per capita carbon emissions in China shown in Table 4 show that the estimated coefficients of environmental decentralization are negative and pass the significance test at least at the 5\% level in Models 1, 3 and 5, indicating that environmental decentralization is beneficial in reducing provincial carbon emissions in China compared to environmental centralization. This result can be explained in two ways. First, environmental decentralization has given local government greater autonomy in environmental management. Compared with the central government, local governments have greater access to local information, and thus are better able to understand the environmental needs of local residents and achieve rational resource allocation at lower costs and with better information, and to formulate targeted environmental policies in terms of emission reduction and green technology, thereby promoting the coordinated development of the local economy and the environment. Secondly, as the degree of environmental decentralization increases, the number of local environmental protection personnel will increase. While promoting the gradual formation of local environmental regulatory networks, local governments can make environmental policy adjustments in real-time according to local environmental conditions, thus ultimately improving local environmental quality. However, it is surprising that the results of this study on the impact of environmental decentralization on carbon emissions are inconsistent with the results of Lu and Zhang (2016), Zhang et al. (2017) and Qi et al. (2014), that is, environmental decentralization is not conducive to carbon emission control, on the contrary, the higher the degree of environmental decentralization, the greater the carbon emissions. They also interpreted this result from the perspective of jurisdictional competition to mean that environmental decentralization would make local governments blindly pursue economic growth at the expense of the environment, resulting in ineffective environmental regulatory standards, which would lead to a "race to the bottom" phenomenon, thereby aggravating environmental pollution and carbon emissions. Although there is some validity in their explanation of the impact of environmental decentralization on carbon emissions, their conclusions are still open to further debate. First, the previous research period mainly focused on 1992-2010 (Lu and Zhang 2016; Zhang et al. 2017; Qi et al. 2014), while this study spanned the period 2000-2017. With the change of time, the era conditions of the impact of environmental decentralization on carbon emissions are changing. In particular, since 2007, the Chinese government has gradually incorporated energy conservation and emission reduction into the local performance appraisal system, and in the context of lifelong accountability and veto system for local officials, local governments' awareness of environmental protection has been strengthened, and local officials can no longer arbitrarily change regional environmental regulations to attract foreign investment as they did in the past, making the GDP championship competition mechanism, which has always emphasized economic growth at the expense of environmental protection, no longer exist due to the loss of environmental institutional foundation. 
Therefore, we can speculate that the conclusions of Lu and Zhang (2016), Zhang et al. (2017) and Qi et al. (2014) that environmental decentralization aggravates carbon emissions may be related to their earlier study period. Second, the local carbon emission reduction incentive mechanism under the decentralized environmental management system is gradually formed. Along with the intensification of local carbon emissions in recent years, China is under tremendous pressure to meet its 2030 national voluntary emissions reduction commitments. Therefore, the Chinese government attaches great importance to carbon emission control, and has gradually made the effective curbing of carbon emissions an important criterion for evaluating the performance of local officials, combining this with economic incentives such as transfer payments to local governments. To a certain extent, this mobilizes local officials to take the initiative and enthusiasm to implement carbon emission reduction. It means that local governments are given more power over environmental management, which may enable them to formulate more accurate environmental regulations and reasonable investment in environmental management according to the local ecological and environmental conditions and economic development level, thus forming an incentive and compatibility mechanism to effectively curb carbon emissions and solve the problem of inconsistent goals and asymmetric information between the central and local governments in carbon emission management, and ultimately reduce carbon emissions throughout China, and improve the effectiveness of environmental management. Therefore, in the case of carbon emissions, a modest decentralization of authority for environmental management and responsibility for carbon emission governance to local governments will facilitate further governance of carbon emissions, while over-centralization may result in increased carbon emissions.

In terms of the effect of fiscal decentralization on carbon emissions, the estimated coefficient of fiscal decentralization is significantly positive at the $1 \%$ level in all three models (Model 2, Model 4 and Model 6), which is consistent with the results of Zhang's (2011) study, that is, the improvement of fiscal decentralization will significantly increase carbon emissions. The reason for this may be that fiscal decentralization significantly reduces local governments' efforts to regulate the environment and their investment in environmental governance, thus hindering the innovative development of low-carbon environmental technologies. Moreover, although increased fiscal autonomy helps to motivate local governments and to some extent plays an important role in motivating local officials to develop the regional economy, this appraisal model of official promotion, which focuses on GDP growth, usually comes at the expense of the environment (Yan 2012; Wang et al. 2014). For these two reasons, fiscal decentralization ultimately leads to increased environmental pollution and rising carbon emissions. The above-mentioned positive correlation between fiscal decentralization and provincial per capita emissions suggests that fiscal autonomy is not suitable for local governments as much as it is for environmental decentralization. At the same time, as analyzed above, it is difficult to reflect the impact of Chinese environmental decentralization on carbon emissions if fiscal decentralization is used as a simple indicator 
621 environmental decentralization and carbon emissions directly from the internal logic of environmental 622 management, and the results may be more suitable for assessing the effect of Chinese environmental 623 federalism.

624 Table 4 Basic regression results of environmental decentralization and provincial carbon emissions in China

\begin{tabular}{|c|c|c|c|c|c|c|}
\hline \multirow[t]{2}{*}{ Variables } & \multicolumn{2}{|c|}{ Ordinary least squares (OLS) } & \multicolumn{2}{|c|}{$\begin{array}{l}\text { Static space panel } \\
\text { regression }\end{array}$} & \multicolumn{2}{|c|}{$\begin{array}{c}\text { Dynamic spatial panel } \\
\text { regression }\end{array}$} \\
\hline & Model 1 & Model 2 & Model 3 & Model 4 & Model 5 & Model 6 \\
\hline L. $\ln \mathrm{PCO}_{2}$ & & & & & $\begin{array}{c}0.3651^{* * *} \\
(0.0284)\end{array}$ & $\begin{array}{c}0.3660^{* * * *} \\
(0.0283)\end{array}$ \\
\hline$E D$ & $\begin{array}{l}-0.1267^{* *} \\
(0.0659)\end{array}$ & & $\begin{array}{l}-0.0922^{* *} \\
(0.0386)\end{array}$ & & $\begin{array}{c}-0.1056^{* * *} \\
(0.0523)\end{array}$ & \\
\hline$F D$ & & $\begin{array}{c}0.1242^{* * *} \\
(0.0252)\end{array}$ & & $\begin{array}{c}0.1608^{* * *} \\
(0.0150)\end{array}$ & & $\begin{array}{l}0.1124^{* * *} \\
(0.0237)\end{array}$ \\
\hline $\ln P G D P$ & $\begin{array}{l}0.9143^{* * *} \\
(0.1413)\end{array}$ & $\begin{array}{l}0.8487^{* * *} \\
(0.4267)\end{array}$ & $\begin{array}{c}0.4169^{* * *} \\
(0.1263)\end{array}$ & $\begin{array}{c}0.3536^{* * *} \\
(0.1249)\end{array}$ & $\begin{array}{c}0.1980^{* * * *} \\
(0.0511)\end{array}$ & $\begin{array}{l}0.1531^{* * * *} \\
(0.0095)\end{array}$ \\
\hline$(\ln P G D P)^{2}$ & $\begin{array}{l}-0.0543 \\
(0.0354)\end{array}$ & $\begin{array}{l}-0.0442 \\
(0.0731)\end{array}$ & $\begin{array}{l}-0.0054 \\
(0.0216)\end{array}$ & $\begin{array}{c}0.0031 \\
(0.0216)\end{array}$ & $\begin{array}{l}-0.0126 \\
(0.0188)\end{array}$ & $\begin{array}{l}-0.0187 \\
(0.0189)\end{array}$ \\
\hline $\ln P D$ & $\begin{array}{l}-0.1475^{*} \\
(0.0825)\end{array}$ & $\begin{array}{l}-0.1138^{*} \\
(0.06970)\end{array}$ & $\begin{array}{l}-0.0192 \\
(0.1209)\end{array}$ & $\begin{array}{l}-0.0215 \\
(0.1788)\end{array}$ & $\begin{array}{l}-0.1567 \\
(0.1584)\end{array}$ & $\begin{array}{l}-0.1295 \\
(0.1562)\end{array}$ \\
\hline$R D$ & $\begin{array}{c}-0.0660^{* * *} \\
(0.0207)\end{array}$ & $\begin{array}{l}-0.0663^{*} \\
(0.0413)\end{array}$ & $\begin{array}{c}-0.1044^{* * *} \\
(0.0194)\end{array}$ & $\begin{array}{c}-0.1052^{* * *} \\
(0.0194)\end{array}$ & $\begin{array}{c}-0.0616^{* * *} \\
(0.0173)\end{array}$ & $\begin{array}{c}-0.0621^{\text {*** }} \\
(0.0174)\end{array}$ \\
\hline$F D I$ & $\begin{array}{l}-0.0154^{* *} \\
(0.0065)\end{array}$ & $\begin{array}{l}-0.0125 \\
(0.0110)\end{array}$ & $\begin{array}{l}-0.0099^{* *} \\
(0.0042)\end{array}$ & $\begin{array}{l}-0.0081 \\
(0.0051)\end{array}$ & $\begin{array}{l}-0.0051 \\
(0.0045)\end{array}$ & $\begin{array}{l}-0.0038 \\
(0.0045)\end{array}$ \\
\hline $\operatorname{lnINDUS}$ & $\begin{array}{l}0.2351^{* * *} \\
(0.0849)\end{array}$ & $\begin{array}{c}0.2413^{* * *} \\
(0.0741)\end{array}$ & $\begin{array}{l}0.2986^{* * *} \\
(0.0726)\end{array}$ & $\begin{array}{l}0.3155^{* * *} \\
(0.0736)\end{array}$ & $\begin{array}{l}0.1594^{* * * *} \\
(0.0541)\end{array}$ & $\begin{array}{l}0.1716^{* * *} \\
(0.0650)\end{array}$ \\
\hline OPEN & $\begin{array}{l}0.1154^{*} \\
(0.0771)\end{array}$ & $\begin{array}{c}0.0810 \\
(0.1312)\end{array}$ & $\begin{array}{l}0.1126^{*} \\
(0.0697)\end{array}$ & $\begin{array}{c}0.0793 \\
(0.0665)\end{array}$ & $\begin{array}{l}0.1182^{* *} \\
(0.0604)\end{array}$ & $\begin{array}{l}0.1364^{* *} \\
(0.0576)\end{array}$ \\
\hline$W^{*} \ln \mathrm{PCO}_{2}$ & & & $\begin{array}{c}0.5328^{* * *} \\
(0.1149)\end{array}$ & $\begin{array}{c}0.5517^{* * *} \\
(0.1143)\end{array}$ & $\begin{array}{l}0.2739^{* *} \\
(0.1140)\end{array}$ & $\begin{array}{l}0.2864^{* *} \\
(0.1135)\end{array}$ \\
\hline Constants & $\begin{array}{l}-0.3704^{*} \\
(0.4568) \\
\end{array}$ & $\begin{array}{l}-0.6521 \\
(0.6601) \\
\end{array}$ & & & & \\
\hline$R^{2}$ & 0.7205 & 0.7153 & 0.8183 & 0.8178 & 0.8620 & 0.8619 \\
\hline $\log -\mathrm{L}$ & & & 315.51 & 314.88 & 377.41 & 377.19 \\
\hline $\begin{array}{c}\text { Individual } \\
\text { Effects/Time Effects }\end{array}$ & $\mathrm{Y} / \mathrm{Y}$ & $\mathrm{Y} / \mathrm{Y}$ & $\mathrm{Y} / \mathrm{Y}$ & $\mathrm{Y} / \mathrm{Y}$ & $\mathrm{Y} / \mathrm{Y}$ & $\mathrm{Y} / \mathrm{Y}$ \\
\hline Sample Size $O b s$ & 450 & 450 & 450 & 450 & 450 & 450 \\
\hline
\end{tabular}

Note: $* * *$, and $* * *$ indicate significance at the $10 \%, 5 \%$, and $1 \%$ levels respectively; values in parentheses are standard errors; $W$ indicates a geographic adjacency matrix; and $Y$ indicates that the variable has been controlled. Same table below. 
estimated coefficients of the spatial lag $\left(W^{*} \ln P \mathrm{CO}_{2}\right)$ are both significantly positive at least at the $5 \%$ level, indicating that there is a significant path dependence (spatial autocorrelation) of carbon emissions among Chinese provinces, that is, the carbon emission level of any province will be influenced by the carbon emissions of the neighboring areas, and the estimated results will be biased if the spatial correlation is ignored. In addition, the first-order lagged term of the explained variable (per capita carbon emissions) is positively correlated with the per capita carbon emissions in the current period at the $1 \%$ level, which indicates that the per capita carbon emissions in each province have obvious continuity and stickiness in time, thus highlighting that carbon emissions have a certain inertia-dependent feature (Zhang et al. 2017), that is to say, the carbon emissions remaining in the atmosphere in the previous period may aggravate the carbon emissions of the region in the current period. Therefore, if short-term carbon emissions are not dealt with in a timely and effective manner, it will lead to long-term and more costly negative environmental effects.

As far as the control variables are concerned, this paper is mainly based on the interpretation of the regression results from the dynamic spatial panel model 5. Table 4 shows that the estimated coefficients of the economic growth variables are significantly positive, indicating that in China's economic transition period, with rapid economic development, increasing energy consumption will significantly increase carbon emissions in each province. It is noteworthy that the squared term coefficient of economic growth is negative but not significant, which indicates that there is an inverted U-shaped Kuznets curve between economic growth and provincial carbon emissions in China. This means that when the economic development reaches a certain level, people's demand for environmental quality will become higher and higher, and local governments will provide some financial and policy support to effectively control carbon emissions, so as to curb carbon emissions and improve environmental quality, but the current effect is not obvious. The relationship between population density and carbon emissions is insignificant but negative, indicating that an increase in population density decreases provincial carbon emissions. The reason for this is that the carbon emissions in this study were measured on a per capita basis, which is not inconsistent with previous findings that population growth contributes to increased carbon emissions (Zhu et al. 2010). Of course, regions with higher population densities usually have more skilled people and capital, which is likely to lead to economic growth and rapid development of carbon abatement technologies, thus reducing carbon emissions. The estimated coefficient of R\&D intensity is significantly negative at the $1 \%$ level, indicating that R\&D intensity has a significant inhibitory effect on carbon emissions, which is consistent with the findings of Cole (2013) and Han (2018), implying that improving energy efficiency by inducing low-carbon technological progress through science and technology innovation is an important means to curb the growth of carbon emissions and effectively promote the achievement of carbon emission reduction targets in China. The estimated coefficient for FDI is negative, but it does not pass the significance test in most of the models (Table 4), indicating that FDI has some inhibitory effect on carbon 
emissions, but the effect is not obvious. This may be due to the fact that China is currently undergoing a transition from quantity to quality of foreign investment. On the one hand, due to the influence of the "pollution refuge" effect, most foreign investors usually move enterprises at the lower end of the value chain and with higher carbon emissions to developing countries, thus exacerbating China's carbon emissions to a certain extent; On the other hand, as China has paid more attention to the "quality" of foreign investment in recent years, it has encouraged localities to prioritize the introduction of enterprises with new technologies and strict implementation of environmental protection standards to achieve clean or green production by reducing energy consumption, thereby reducing carbon emissions and exerting a "pollution halo" effects. With these two opposite directions, the positive environmental effects of FDI due to technology transfer (carbon abatement effects) are likely to be partially offset by the negative environmental effects they generate (increased carbon emissions), resulting in insignificant effects of FDI in curbing carbon emissions. The impact of industrial structure on carbon emissions, as measured by the proportion of industry, is significantly positive at the $1 \%$ level, indicating that the high proportion of secondary industries is an important factor contributing to the increase in carbon emissions, and also indicating that the impact of industrial structure on carbon emissions cannot be ignored. This means that although China is currently accelerating the transformation, upgrading and greening of its industrial structure, it has not fundamentally reversed the extensive economic growth model of industrial development, and the growth of industrial output is still at the expense of massive primary energy consumption and environmental sacrifice (Zhang et al. 2020), which in turn leads to increased carbon emissions and serious environmental pollution. Therefore, the development of new and strategic industries based on clean production and the reduction of dependence on resource-based industries are still important means to reduce carbon emissions. In addition, the effect of trade openness on carbon emissions is also significantly positive, indicating that trade openness has a significant role in promoting the growth of per capita carbon emissions in the province, which is not conducive to energy conservation and emission reduction. The reason may be related to the negative function of trade openness in transferring environmental pollution. It has been reported that environmental pollution is transferred from areas with stronger environmental regulations to areas with weaker environmental regulations through trade openness, and that less stringent environmental regulations usually promote economic growth, which in turn can lead to more carbon emissions everywhere.

The impact of decomposition indicators of environmental decentralization on China's carbon emissions

In order to further explore the impact of environmental decentralization on provincial carbon emissions in China, the three decomposition indicators of environmental decentralization are re-estimated by dynamic spatial measurement in this paper. The results in Table 5 show that the estimated coefficient of environmental administrative decentralization is negative and significant at the $1 \%$ level, indicating that 
higher environmental administrative decentralization is beneficial to local environmental administrations in arranging reasonable investment in environmental governance and adjusting environmental policies in a scientific and timely manner according to the local social, economic and ecological conditions, thus forming a "race to the top" in environmental administrative matters. The mechanism of healthy competition will ultimately reduce carbon emissions everywhere. The estimated coefficient of environmental monitoring decentralization is also significantly negative at the $1 \%$ level, indicating that the decentralization of environmental monitoring will also suppress local carbon emissions. This is because local governments have more advantages than the central government in environmental quality monitoring, assessment and early warning, so a moderate increase in environmental monitoring decentralization is more conducive to local environmental protection departments effectively carrying out environmental monitoring activities and environmental quality assessment, thus providing more accurate environmental quality information to environmental administration and environmental supervision departments to some extent, and improving environmental quality and reducing carbon emissions. It is noteworthy that the absolute value of the estimated coefficient of the environmental monitoring decentralization is the smallest among the three decomposers, which may be related to the fact that the role of environmental monitoring on carbon emissions is mainly indirect through the provision of environmental information for environmental administration and inspection. In contrast to the environmental administration and environmental monitoring decentralization, the estimated coefficient for the environmental supervision decentralization is significantly positive at the $1 \%$ level, indicating that the decentralization of environmental supervision would increase carbon emissions. This is because environmental supervision departments are the most direct pollution emission control departments, and their environmental supervision services (mainly including environmental enforcement and environmental supervision) are usually influenced by both the local government's primary goal of economic development and excessive regulation by higher-level environmental protection departments, so that local implementation may face greater resistance and affect the supervision effect. In particular, when environmental supervision conflicts with local economic interests, local environmental protection departments will be interfered by local governments in the pursuit of economic growth and environmental supervision and enforcement, thus relaxing environmental regulations in terms of emissions declaration, environmental project acceptance, environmental enforcement and inspection, and thus increasing carbon emissions. Therefore, on the premise of advocating green GDP development and reforming performance assessment standards, the power of environmental supervision should be appropriately shifted upward, and supplemented by the coordination and supervision of the central government, which is the only way to exert the inhibiting effect of environmental supervision on carbon emissions.

Table 5 Dynamic spatial regression results of different environmental decentralization and provincial carbon emissions 


\begin{tabular}{|c|c|c|c|}
\hline & Model 7 & Model 8 & Model 9 \\
\hline$E A D$ & $\begin{array}{l}-0.0814^{* * *} \\
(0.0108)\end{array}$ & & \\
\hline$E S D$ & & $\begin{array}{l}0.0725^{* * *} \\
(0.0228)\end{array}$ & \\
\hline$E M D$ & & & $\begin{array}{c}-0.0306^{* * *} \\
(0.0086)\end{array}$ \\
\hline Control Variables & Y & Y & $\mathrm{Y}$ \\
\hline L. $\ln \mathrm{PCO}_{2}$ & $\begin{array}{l}0.3540^{* * *} \\
(0.0283)\end{array}$ & $\begin{array}{l}0.3509^{* * *} \\
(0.0281)\end{array}$ & $\begin{array}{l}0.3547^{* * * *} \\
(0.0284)\end{array}$ \\
\hline$W^{*} \ln \mathrm{PCO}_{2}$ & $\begin{array}{c}0.3402^{* * *} \\
(0.1123)\end{array}$ & $\begin{array}{c}0.3498^{* * *} \\
(0.1121)\end{array}$ & $\begin{array}{c}0.3415^{* * *} \\
(0.1123)\end{array}$ \\
\hline$R^{2}$ & 0.8646 & 0.8674 & 0.8645 \\
\hline $\log -L$ & 381.74 & 386.43 & 381.48 \\
\hline $\begin{array}{c}\text { Individual Effects/Time } \\
\text { Effects }\end{array}$ & $\mathrm{Y} / \mathrm{Y}$ & $\mathrm{Y} / \mathrm{Y}$ & $\mathrm{Y} / \mathrm{Y}$ \\
\hline Sample Size & 450 & 450 & 450 \\
\hline
\end{tabular}

The impact of interaction between environmental decentralization and fiscal decentralization on carbon emissions in China

In order to explore the impact of the interaction of environmental and fiscal decentralization on carbon emissions under the fiscal decentralization system, the interaction terms of environmental decentralization and fiscal decentralization variables were added to the model and the results are listed in Table 6 . Table 6 shows that the regression coefficients of the interaction terms of environmental decentralization and fiscal decentralization, environmental administrative decentralization and fiscal decentralization, environmental monitoring decentralization and fiscal decentralization, environmental supervision decentralization and fiscal decentralization are all significantly positive at the $5 \%$ level, indicating that the combination of different types of environmental decentralization and fiscal decentralization will promote carbon emissions in each province, and the increase of fiscal autonomy is not conducive to the suppression of carbon emissions by environmental decentralization, which also means that the impact of environmental decentralization on carbon emissions will be constrained to some extent by fiscal decentralization after the integration of environmental decentralization and fiscal decentralization. The reason for this is that fiscal decentralization gives local governments more financial autonomy and economic incentives, while environmental decentralization gives local governments the power to protect and manage the environment. When local governments have the financial autonomy delegated by the central government and the ability to intervene in local environmental matters, they usually sacrifice the environment for rapid economic growth, and even the phenomenon of government-to-government "free-riding" and "government-business collusion" occurs. When the environmental degradation effect of fiscal decentralization is greater than the inhibitory effect of environmental decentralization on carbon emissions, carbon emissions will be 
753

754

755

756

757

758

759

760

761

762

763

764

765

766

767

768

769

770

771

772

intensified. The empirical results in this paper support the findings of Tian and Wang (Tian et al. 2018). Although the relationship between fiscal decentralization and carbon emissions has been discussed in many studies (Zhang et al. 2011; Ran et al. 2020; Yan 2012; Wang et al. 2014), this study is more relevant because it fits into the theory of environmental federalism.

In addition, comparing the regression coefficients of the interaction terms in Table 6, it is found that the decentralization of the environmental system is the largest, the decentralization of environmental administration is the second largest, and the decentralization of environmental supervision and monitoring is the smallest, and the reason for this difference may be related to the distribution of environmental powers set up by the environmental authorities. The environmental system department, which is the prime minister's agency for environmental governance, has the highest estimated interaction coefficients because its environmental powers are most affected by the increase in financial autonomy; the environmental administration department, which is responsible for formulating environmental policies and coordinating resource allocation, has the second-highest estimated interaction coefficients because these powers are weakened to a large extent by financial decentralization, which in turn affects the inhibitory effect of environmental decentralization on the growth of carbon emissions; and the environmental monitoring department and the environmental supervision department, which are the concrete implementers of environmental protection, are less affected by fiscal decentralization because their functions are non-substitutional, so their interaction coefficients are smaller.

Table 6 Dynamic spatial regression results of the interaction between environmental decentralization and fiscal

decentralization on China's provincial carbon emissions

\begin{tabular}{ccccc}
\hline Variables & $X=E D$ & $X=E A D$ & $X=E S D$ & $X=E M D$ \\
\hline$L . \ln P C O_{2}$ & $0.3512^{* * *}$ & $0.3543^{* * *}$ & $0.3485^{* * * *}$ & $\left(0.3558^{* * *}\right.$ \\
$X$ & $(0.0285)$ & $(0.02836)$ & $(0.0279)$ & $-0.1491^{* *}$ \\
& $-0.1007^{* *}$ & $-0.1635^{* *}$ & $0.0731^{* *}$ & $(0.0542)$ \\
$F D$ & $(0.0507)$ & $(0.0680)$ & $(0.0267)$ & $0.1162^{* * *}$ \\
& $0.1301^{* * *}$ & $0.0933^{* * *}$ & $0.1163^{* * *}$ & $(0.0323)$ \\
$X^{*} F D$ & $(0.0171)$ & $(0.0211)$ & $(0.0241)$ & $0.0574^{* *}$ \\
& $0.0784^{* *}$ & $0.0643^{* *}$ & $0.0587^{* *}$ & $(0.0201)$ \\
Control Variables & $(0.0146)$ & $(0.0184)$ & $(0.0180)$ & $\mathrm{Y}$ \\
$W^{*}$ lnPCO 2 & $\mathrm{Y}$ & $\mathrm{Y}$ & $\mathrm{Y}$ & $0.3467^{* * *}$ \\
& $0.3283^{* * *}$ & $0.3379^{* * *}$ & $0.3440^{* * *}$ & $(0.1125)$ \\
\hline$R^{2}$ & $(0.1127)$ & $(0.1124)$ & $(0.1121)$ & 0.8560 \\
Log-L & 0.8652 & 0.8650 & 0.8683 & 382.34 \\
Individual & 382.63 & 382.33 & 387.98 & $\mathrm{Y} / \mathrm{Y}$ \\
Effects/Time Effects & $\mathrm{Y} / \mathrm{Y}$ & $\mathrm{Y} / \mathrm{Y}$ & $\mathrm{Y} / \mathrm{Y}$ & 450 \\
Sample Size & 450 & 450 & 450 & \\
\hline
\end{tabular}


Decentralization, Environmental Supervision Decentralization and Environmental Monitoring Decentralization, respectively. The same table below.

Estimates of the impact of environmental decentralization on carbon emissions at different regions in China

Considering the spatial heterogeneity of environmental decentralization levels in different regions and the differences in resource endowment, economic development and technological innovation, this paper divided mainland China into eastern, central and western regions according to their economic development levels, and explored the heterogeneity of environmental decentralization's impact on carbon emissions from a regional perspective. The empirical results of the impact of environmental decentralization on carbon emissions in different regions are shown in Table 7. From the regression results, the regression coefficients of environmental decentralization and its disaggregated variables in the eastern region are negative (except for environmental supervision decentralization) but not significant, indicating that the decentralization of environmental management in this region is conducive to reducing carbon emissions, further indicating that environmental decentralization is an important means of energy conservation and emission reduction in the eastern region, but the positive effect has not yet fully emerged. This may be due to the fact that the eastern part of the country is economically more developed, and local governments have already attached a certain degree of importance to environmental protection, and technological innovation and human capital have a stronger driving effect on the upgrading of the regional industrial structure; in addition, the distribution of environmental protection personnel at the grass-roots level in the eastern part of the country is already at a high level, thus weakening the inhibitory effect of environmental decentralization on carbon emissions. The estimated coefficients on the environmental decentralization, environmental administrative decentralization and environmental supervision decentralization variables are significantly positive at the $10 \%$ level in the central region compared to the eastern region, suggesting that environmental decentralization in the central region contributes to the increase in carbon emissions, although environmental monitoring decentralization helps to curb carbon emissions in the central region (the coefficient on environmental monitoring decentralization is significantly negative), overall decentralization of environmental management matters are not conducive to carbon reduction in the region. This may be due to the relatively lagging economic development in the central region, where local governments are heavily influenced by incentives for economic growth, and environmental decentralization facilitates local governments to focus more on economic development and at the expense of the environment. Therefore, the existing performance appraisal system in the central region should be reformed and environmental management powers (such as environmental administration and environmental supervision) in the area of carbon emissions should be appropriately transferred upwards to avoid the negative impact of excessive environmental decentralization on carbon emission reduction. The coefficients of environmental decentralization, environmental administrative decentralization and environmental monitoring decentralization in western China are all 
significantly negative at the $5 \%$ level, while environmental supervision decentralization has a significant positive correlation with the growth of carbon emissions (Table 7), indicating that environmental decentralization has a greater impact on carbon emissions in western China than in eastern and central China. The reason for this is that the western region is currently in the stage of shifting from the stage of laying the foundation for western development (2000-2010) to the stage of accelerated development (2010-2030), and the conflict between economic development and resources and environment in this region is the most intense, and the ecological environment is very fragile. In addition to adjusting the industrial structure, improving the investment environment and developing infrastructure such as science, technology and education, the construction of the ecological environment is also its main task. Especially in recent years, the central government has increased its intervention in the ecological and environmental protection of western regions, and has made the environmental protection of key ecological function areas in western regions an important indicator in local performance appraisals, while giving local governments in western regions sufficient incentives and necessary policy support for environmental protection. In this context, once the environmental management is decentralized, it will make up for the shortcomings of the environmental management system in the past, which will lead to the gradual formation of a more comprehensive environmental regulatory mechanism in the western grassroots regions, and enable local governments to formulate environmental policies and control carbon emissions on time by virtue of the emerging information and resource allocation advantages. As a result, the increase in environmental decentralization in the west has a greater dampening effect on carbon emissions than in the east and central regions. It is worth mentioning that the regression coefficients of environmental supervision decentralization in the eastern, central and western regions are positive, but only in the western region passed the 5\% significance test, indicating that the promotion effect of environmental supervision decentralization on the growth of carbon emissions in China is more pronounced in the western region. This is mainly because the western region has a lower level of economic development than the eastern and central regions, and local governments are more influenced by the incentives of economic growth, and the contradiction between environmental supervision and local economic development is greater than that in the eastern and central regions, which leads to greater resistance to the implementation of environmental supervision in the western region and ultimately affects the inspection effect. Therefore, it is necessary to appropriately transfer the power of environmental supervision upwards and to manage environmental inspection matters vertically.

Table 7 shows that the estimated coefficients of the impact of fiscal decentralization on carbon emissions are positive in the eastern, central and western regions, indicating that an increase in the degree of fiscal decentralization contributes to the growth of carbon emissions, but the extent to which fiscal decentralization affects the growth of carbon emissions varies across regions. In the eastern region, there is no significant positive correlation between fiscal decentralization and carbon emissions, and the regression 
coefficients are the smallest, while in the central and western regions, the two show significant positive correlation at the level of at least $5 \%$ and $10 \%$, respectively. The reasons for this difference may be related to the different incentives created by the economic development and financial resources of each region, as well as the differences in resource endowments due to the ecological situation. In the eastern region, economic development and financial resources are higher, local governments prefer the environment over economic growth incentives, thus in the context of fiscal decentralization, local environmental protection departments are determined to implement environmental protection policies, making fiscal decentralization have less influence on environmental management matters, thus resulting in fiscal decentralization has the weakest effect on the growth of carbon emissions; in the central region, because of the relative lag in economic development, fiscal decentralization gives local governments much greater incentives to develop the economy than local governments' preferences for the environment. Thus, as fiscal autonomy increases, local governments make way for economic development by reducing environmental regulations or distorting environmental policies, resulting in the strongest contribution of fiscal decentralization to increasing carbon emissions. As for the western region, although the level of economic development is the lowest and local governments are more influenced by the incentives for economic development given by fiscal decentralization, the central and local governments have paid more attention to environmental issues in the western region and have given sufficient incentives for environmental protection due to the fragile ecological environment of the region. Thus, even though local governments still have strong incentives for economic development, economic development at the expense of the environment has been largely curbed. As a result, the regression coefficient of the impact of fiscal decentralization on carbon emissions in the western region is small and only significantly positive at the $10 \%$ level.

The impact of the interaction term between environmental decentralization and its decomposition variables and fiscal decentralization on regional carbon emissions shows some heterogeneity (Table 7). In the eastern region, the coefficients of the interaction terms are all negative, indicating that the combination of environmental decentralization and its disaggregated variables with fiscal decentralization will have a restraining effect on carbon emissions in the eastern region; while in the central and western regions, the coefficients of the interaction terms are all positive and significant in the western region, except for the central region, where the coefficients of the interaction terms of environmental decentralization and environmental administrative decentralization with fiscal decentralization are negative, indicating that most of the interaction term between the decentralization variable and fiscal decentralization in the central and western regions promote carbon emissions. This is mainly because the central and western regions are relatively underdeveloped, and local governments have stronger incentives to pursue economic growth than the eastern regions, even squeezing out environmental protection spending for high-return productive investments, thus leading to an increase in the hindering effect of fiscal decentralization on the management of local environmental affairs; while in the economically developed eastern regions, local 
879

880

881

882

883

884

885

886

887

888

889

890

891

892

893

894

895

896

897

898

governments have a stronger preference for the environment and have relatively sufficient funds to control environmental pollution, so fiscal decentralization interferes less with environmental management matters, resulting in the inhibitory effect of the interaction terms on carbon emissions.

In addition, the period lag coefficients, spatial autocorrelation coefficients, and the effects of other control variables for carbon emissions (not listed due to space limitations) are all generally consistent with the results in Table 4 and will not be repeated here. It is worth pointing out that the coefficient of the spatial lag term of carbon emissions in the eastern region is positive but not significant, while the coefficient of the spatial lag term in the central and western regions is significantly positive at least at the 5\% level (Table 7), which reflects that there is still an obvious path dependence of carbon emissions in the central and western regions, while the positive spatial correlation of carbon emissions in the eastern region is weakening. The reason for this may be that the eastern region has high-technology and high-efficiency resources that are constantly flowing to Beijing, Tianjin, Shanghai and other regions, coupled with the gradual transfer of high-energy consumption and high-emission industries in these regions to provinces and regions with lower environmental regulations in close proximity, leading to a significant decline in carbon emissions in the above-mentioned regions, while carbon emissions in relatively backward eastern provinces such as Liaoning, Hebei and Fujian have declined less (Liu et al. 2018), thus weakening the positive spatial correlation of carbon emissions within the region; the economic development of the central and western regions mainly relies on the region's resource endowments and the transfer of industries from the eastern region, with obvious synergistic development effects, resulting in a strong spatial dependence of carbon emissions within the region. 
Table 7 dynamic spatial regression results of environmental decentralization and its interaction with administrative decentralization on carbon emissions in different regions of China

\begin{tabular}{|c|c|c|c|c|c|c|c|c|c|c|c|c|}
\hline \multirow{2}{*}{ Variables } & \multicolumn{4}{|c|}{ Eastern Region } & \multicolumn{4}{|c|}{ Central Region } & \multicolumn{4}{|c|}{ Western Region } \\
\hline & $X=E D$ & $X=E A D$ & $X=E S D$ & $X=E M D$ & $X=E D$ & $X=E A D$ & $X=E S D$ & $X=E M D$ & $X=E D$ & $X=E A D$ & $X=E S D$ & $X=E M D$ \\
\hline \multirow[t]{2}{*}{ L. $\ln \mathrm{PCO}_{2}$} & $0.0816^{* *}$ & $0.1402^{* * * *}$ & $0.0993^{* *}$ & $0.0928^{* * *}$ & $0.2048^{* * * *}$ & $0.2142^{* * * *}$ & $0.1929^{* * * *}$ & $0.2181^{* * * *}$ & $0.2537^{* * * *}$ & $0.2593^{* * * *}$ & $0.2581^{* * *}$ & $0.2570^{* * *}$ \\
\hline & $(0.0468)$ & $(0.0460)$ & $(0.0465)$ & $(0.0434)$ & $(0.0785)$ & $(0.0781)$ & $(0.0781)$ & $(0.0785)$ & $(0.0477)$ & $(0.0490)$ & $(0.0491)$ & $(0.0483)$ \\
\hline \multirow[t]{2}{*}{$X$} & -0.1399 & -0.1024 & 0.1016 & -0.0714 & $0.2545^{*}$ & $0.4120^{*}$ & $0.2584^{*}$ & $-0.0762^{*}$ & $-0.3023^{* *}$ & $-0.1355^{* *}$ & $0.1346^{* *}$ & $-0.0933^{* *}$ \\
\hline & $(0.1483)$ & $(0.0980)$ & $(0.1077)$ & $(0.1442)$ & (0.1094) & $(0.2103)$ & $(0.1612)$ & $(0.0384)$ & $(0.1020)$ & $(0.0461)$ & $(0.0385)$ & $(0.0273)$ \\
\hline \multirow[t]{2}{*}{$F D$} & 0.0424 & 0.02315 & 0.0142 & 0.0356 & $0.1581^{* *}$ & $0.2105^{* * *}$ & $0.1490^{* *}$ & $0.1329^{* *}$ & $0.0527^{*}$ & $0.0312^{*}$ & $0.0221^{*}$ & $0.0394^{*}$ \\
\hline & $(0.0864)$ & $(0.0384)$ & $(0.0412)$ & $(0.0885)$ & $(0.0419)$ & $(0.0228)$ & $(0.0208)$ & $(0.0126)$ & (0.0369) & $(0.0215)$ & $(0.0146)$ & $(0.0285)$ \\
\hline \multirow[t]{2}{*}{$X^{*} F D$} & -0.0698 & -0.1025 & -0.0470 & -0.0481 & -0.0572 & -0.1618 & 0.0684 & 0.0446 & $0.0387^{* *}$ & $0.0289^{* *}$ & $0.0741^{* *}$ & $0.0257^{* *}$ \\
\hline & $(0.1010)$ & $(0.0501)$ & $(0.0651)$ & $(0.0890)$ & $(0.1122)$ & $(0.1104)$ & $(0.0763)$ & $(0.0522)$ & (0.0113) & $(0.0078)$ & $(0.0391)$ & $(0.0171)$ \\
\hline Control Variables & $\mathrm{Y}$ & $\mathrm{Y}$ & $\mathrm{Y}$ & $\mathrm{Y}$ & $\mathrm{Y}$ & $\mathrm{Y}$ & $\mathrm{Y}$ & $\mathrm{Y}$ & $\mathrm{Y}$ & $\mathrm{Y}$ & $\mathrm{Y}$ & $\mathrm{Y}$ \\
\hline \multirow[t]{2}{*}{$W^{*} \ln \mathrm{PCO}_{2}$} & 0.1327 & 0.1686 & 0.1205 & 0.1887 & $0.2240^{* *}$ & $0.2765^{* *}$ & $0.2042^{* *}$ & $0.2485^{* *}$ & $0.5071^{* * *}$ & $0.5280^{* * *}$ & $0.5352^{* * *}$ & $0.5279^{* * *}$ \\
\hline & $(0.1398)$ & $(0.1411)$ & $(0.1413)$ & $(0.1393)$ & $(0.1038)$ & $(0.1064)$ & $(0.1027)$ & $(0.0516)$ & $(0.1778)$ & $(0.1796)$ & $(0.1785)$ & $(0.1783)$ \\
\hline$R^{2}$ & 0.9017 & 0.8959 & 0.8983 & 0.9057 & 0.8556 & 0.8578 & 0.8575 & 0.8556 & 0.9082 & 0.9025 & 0.9041 & 0.9016 \\
\hline Log-L & 202.78 & 198.03 & 199.99 & 206.17 & 102.58 & 103.52 & 103.38 & 102.61 & 143.60 & 136.54 & 136.51 & 137.91 \\
\hline Individual Effects/Time & $\mathrm{Y} / \mathrm{Y}$ & $\mathrm{Y} / \mathrm{Y}$ & $\mathrm{Y} / \mathrm{Y}$ & $\mathrm{Y} / \mathrm{Y}$ & $\mathrm{Y} / \mathrm{Y}$ & $\mathrm{Y} / \mathrm{Y}$ & $\mathrm{Y} / \mathrm{Y}$ & $\mathrm{Y} / \mathrm{Y}$ & $\mathrm{Y} / \mathrm{Y}$ & $\mathrm{Y} / \mathrm{Y}$ & $\mathrm{Y} / \mathrm{Y}$ & $\mathrm{Y} / \mathrm{Y}$ \\
\hline \multicolumn{13}{|l|}{ Effects } \\
\hline Sample Size & 165 & 165 & 165 & 165 & 120 & 120 & 120 & 120 & 165 & 165 & 165 & 165 \\
\hline
\end{tabular}

900 Note: According to the National Development and Reform Commission, the eastern region includes 11 provinces (cities) of Beijing, Tianjin, Hebei, Liaoning, Shanghai, Jiangsu, Zhejiang,

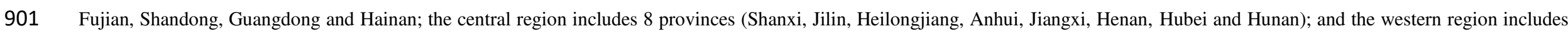

11 provinces (autonomous regions) of Inner Mongolia, Guangxi, Chongqing, Sichuan, Guizhou, Yunnan, Shaanxi, Gansu, Qinghai, Ningxia and Xinjiang. 


\section{Robustness test of the impact of environmental decentralization on carbon emissions}

In order to test the robustness and validity of the above empirical results, this paper referred to the method of $\mathrm{Lu}$ (2016) for calculating the environmental decentralization, and remeasures the environmental decentralization and its three decomposition indexes without considering the economic scale reduction factor, and regressed them with the per capita carbon emissions of Chinese provinces, and the results of the robustness test are listed in Table 8. Comparing with the results in Tables 4-6, it is found that the relationship between environmental decentralization, environmental administrative decentralization, environmental monitoring decentralization and environmental supervision decentralization, which do not take into account the economic scale reduction factor, and carbon emissions all remain stable. In addition, although the regression coefficients of other variables change to different degrees, the direction and significance of the changes are basically the same as the previous results, which indicates that the estimation results in this paper are more robust.

Table 8 Estimation results of the robustness test

\begin{tabular}{|c|c|c|c|c|}
\hline Variables & $X=E D$ & $X=E A D$ & $X=E S D$ & $X=E M D$ \\
\hline \multirow[t]{2}{*}{ L. $\ln \mathrm{PCO}_{2}$} & $0.3523^{* * *}$ & $0.3538^{* * *}$ & $0.3469^{* * *}$ & $0.3540^{* * *}$ \\
\hline & $(0.0284)$ & $(0.0284)$ & $(0.0283)$ & $(0.0284)$ \\
\hline \multirow[t]{2}{*}{$X$} & $-0.1169^{* * *}$ & $-0.0110^{* * *}$ & $0.0723^{* * * *}$ & $-0.0531^{* * *}$ \\
\hline & $(0.0128)$ & $(0.0036)$ & $(0.0268)$ & $(0.0126)$ \\
\hline \multirow[t]{2}{*}{$F D$} & $0.1016^{* * *}$ & $0.0812^{* * *}$ & $0.0918^{* * *}$ & $0.1134^{* * *}$ \\
\hline & $(0.0128)$ & $(0.0129)$ & $(0.0103)$ & $(0.0129)$ \\
\hline Control Variables & $\mathrm{Y}$ & $\mathrm{Y}$ & $\mathrm{Y}$ & $\mathrm{Y}$ \\
\hline \multirow[t]{2}{*}{$W^{*} \ln \mathrm{PCO}_{2}$} & $0.3278^{* * * *}$ & $0.3386^{* * *}$ & $0.3519^{* * *}$ & $0.3398^{* * *}$ \\
\hline & $(0.1134)$ & $(0.1129)$ & $(0.1127)$ & $(0.1129)$ \\
\hline$R^{2}$ & 0.8647 & 0.8644 & 0.8666 & 0.8644 \\
\hline $\log -\mathrm{L}$ & 381.90 & 381.43 & 384.98 & 381.38 \\
\hline $\begin{array}{c}\text { Individual } \\
\text { Effects/Time Effects }\end{array}$ & $\mathrm{Y} / \mathrm{Y}$ & $\mathrm{Y} / \mathrm{Y}$ & $\mathrm{Y} / \mathrm{Y}$ & $\mathrm{Y} / \mathrm{Y}$ \\
\hline Sample Size & 450 & 450 & 450 & 450 \\
\hline
\end{tabular}

\section{Conclusions and policy recommendations}

To achieve the set 2030 carbon emission reduction target in China, it is necessary to construct a reasonable environmental management system for carbon emissions among government levels. This article empirically examined environmental decentralization and its impact on carbon emissions in the context of fiscal decentralization by constructing a dynamic spatial panel model using inter-provincial panel data from 2003 to 2017 in China. The results show that: (1) The period lag and spatial lag coefficients of carbon 
emissions are both significantly positive, indicating that there is an obvious inertia dependence (continuity) and spatial path dependence of carbon emissions in China, with high-high and low-low aggregation characteristics. (2) At the national level, considering the spatial spillover effect of carbon emissions, the overall environmental decentralization, environmental administrative decentralization and environmental monitoring decentralization have a significant and stable negative impact on carbon emissions, indicating that environmental administrative decentralization, environmental monitoring decentralization and overall environmental decentralization are conducive to reducing carbon emissions in China, while environmental supervision decentralization plays a significant and stable role in promoting carbon emissions, implying that, compared with environmental centralization, the current environmental decentralization system is generally conducive to carbon emission control, but environmental supervision decentralization has certain negative effects on carbon emission reduction. Fiscal decentralization significantly exacerbates carbon emissions, because fiscal decentralization is prone to distort incentives and significantly reduces local governments' efforts to regulate the environment, thus failing to impose effective constraints on carbon emissions; the interaction term coefficients of environmental decentralization and its disaggregated indicators and fiscal decentralization are both significantly positive at the 5\% level, showing that the combination of environmental management rights and fiscal autonomy will have a facilitating effect on carbon emissions, implying that fiscal decentralization weakens the incentives of environmental decentralization for environmental protection and thus exacerbates carbon emissions. (3) At the regional level, there is great spatial heterogeneity in the effects of environmental decentralization on carbon emissions in different regions. The suppression effect of environmental decentralization, environmental administrative decentralization and environmental monitoring decentralization on carbon emissions in the western region is significantly larger than that in the eastern region; similarly, the promotion effect of environmental supervision decentralization on carbon emissions is also more significant than that in the eastern region. In the central region, in addition to the environmental monitoring decentralization inhibits carbon emissions, environmental decentralization, environmental administration decentralization and environmental supervision decentralization promote carbon emissions, indicating that the decentralization of environmental management in the central region does not form an effective incentive for carbon emission management in general, and is not conducive to the implementation of carbon emission reduction. The promotion effect of fiscal decentralization in the eastern part of the country is significantly weaker than that in the central and western part of the country, but the combination of environmental decentralization and its decomposition index with fiscal decentralization is significantly better than that in the central and western part of the country in terms of its inhibiting effect on carbon emissions.

The above results have important implications for the construction of an environmental management system for carbon emissions in China. Based on the empirical results, this paper makes the following policy recommendations: (1) At the national level, the degree of environmental decentralization can be increased, 
and the setting of environmental management agencies and the allocation of environmental protection personnel among different levels of government can be further optimized, so as to improve the efficiency of local government's control over carbon emissions. At the same time, accountability, a veto system and a green GDP assessment system should be implemented to prevent the exacerbation of carbon emissions caused by the excessive combination of fiscal and environmental decentralization, thus reducing the negative impact of fiscal decentralization on carbon emission reduction management. (2) For different types of environmental decentralization, different degrees of decentralization should be adopted. Environmental administrative powers and environmental monitoring powers can be appropriately decentralized in order to make full use of the cost and information advantages of local governments to achieve effective resource allocation in carbon emission control and environmental management, thereby reducing the level of carbon emissions. The power of environmental supervision should be centralized to ensure the authority of environmental inspection, supplemented by the coordination and supervision of the central government, so as to avoid the "bottom-up competition" of carbon emissions by local governments for the sake of economic development. (3) Considering regional heterogeneity, differentiated environmental decentralization strategies should be scientifically formulated in the three major regions of East, Central and West. Specifically, as the eastern regions have obvious advantages in economy, technology, talent and information, and have formed a comprehensive management system for carbon emission management, the central government should further decentralize environmental administration and environmental monitoring, and establish a comprehensive local environmental information disclosure mechanism to ensure the openness and transparency of environmental monitoring data. In the central region, the central government should increase its efforts to intervene and inspect local environments, transfer upward environmental administrative and supervision powers, appropriately reduce the discretionary space of local governments in the formulation of environmental policies, and form an appropriate vertical management system, while a moderate downward transfer of environmental monitoring powers can be considered. In the western region, given the fragility and importance of the region's ecological environment, the central government should grant special treatment to the western region in terms of environmental decentralization. First, in environmental administration and environmental monitoring, it should increase the administrative and monitoring powers of local governments as well as the number of local environmental protection personnel, upgrade environmental infrastructure and environmental monitoring capacity, and gradually improve the grassroots environmental management network in the western region so as to guide local governments to "compete upward" in carbon emission control. Secondly, in environmental supervision, while transferring the power of environmental supervision, the central government should give greater policy preference to environmental inspection matters, and in environmental supervision matters to strengthen local government incentives and constraints on carbon emission reduction, and ultimately form a situation where the incentives for central and regional 
environmental management are compatible. (4) Considering the negative spatial externalities and spillover effects of carbon emissions, the establishment of a cross-regional and cross-sectoral "joint prevention and control" carbon emissions governance mechanism is an important option to avoid local governments "going it alone" and to curb carbon emissions "free-riding" behavior. "

It is worth pointing out that, due to the limitations of data and environmental decentralization measurement methods, this paper discussed the carbon emission effects of environmental decentralization in China from the inter-provincial panel, while the extent of environmental decentralization and its impact on carbon emissions at the inter-municipal level is still unknown. In addition, this article mainly analyzed the effects of environmental decentralization based on the government's actions, but does not consider the effects of other social actors. Therefore, it will be the focus of future research to improve the environmental decentralization indexes from the inter-provincial perspective, and to investigate the environmental decentralization effects of other entities and the effects of different environmental decentralization degrees.

Authors Contributions L.X.Z. and Y.X. designed the study and performed the analysis, Y.X. prepared the manuscript and L.X.Z. revised the original manuscript.

Funding The research was funded by the National Social Science Foundation of China (No.17BGL138), and Hunan Social Science Fund (No.18YBA151).

Availability of data and materials All data are processed by the author, true and effective.

\section{Declarations}

Ethical Approval All procedures performed in studies involving human participants were in accordance with the ethical standards of the institutional and/or national research committee.

Consent to Participate Informed consent was obtained from all individual participants included in the study.

Consent to Publish The manuscript is approved by all authors for publication.

Competing Interests The authors declare no competing interests.

\section{References}

Anselin L (2001) Spatial effects in econometric practice in environmental and resource economics. American Journal of Agricultural Economics 83(3):705 - 710. https://doi.org/10.1111/0002-9092.00194

Bai JH, Nie L (2017) Is environmental decentralization really exacerbating haze pollution. China Population Resources and Environment 27(12):59-69. (In Chinese) https://doi.org/10.12062/cpre.20170911

Banzhaf HS, Chupp BA (2012) Fiscal federalism and interjurisdictional externalities: new results and an application to US air pollution. Journal of Public Economics 96(5/6):449-464. https://doi.org/10.1016/j.jpubeco.2012.01.001

Ben YH, Li XD (2017) Fiscal decentralization and environmental pollution: An empirical analysis based on spatial measurement. China Science and Technology Forum 6:109-114. (In Chinese) https://doi.org/10.13580/j.cnki.fstc.2017.06.015

Besley T, Coate S (2003) Centralized versus decentralized provision of local public goods: A political economy approach. 
Burgess R, Hansen M, Olken BA, et al (2012) The political economy of deforestation in the tropics. Quarterly Journal of Economics 127(4):1707-1754. https://doi.org/10.1093/qje/qjs034

Cole MA, Elliott RJR, Okubo T, et al (2013) The carbon dioxide emissions of firms: A spatial analysis. Journal of Environmental Economics and Management 65(2):290 - 309. https://doi.org/10.1016/j.jeem.2012.07.002

Deng HH, Zheng XY, Huang N, et al (2012) Strategic interaction in spending on environmental protection: spatial evidence from Chinese cities. China \& World Economy 20(5):103 - 120. https://doi.org/10.1111/j.1749-124X.2012.01304.x

Dijkstra BR, Fredriksson PG (2010) Regulatory environmental federalism. Annual Review of Resource Economics 2(1):319-339. https://doi.org/10.1146/ANNUREV-RESOURCE-040709-135112

Feng C, Wang M, Liu GC, et al (2017) Green development performance and its influencing factors: a global perspective. Journal of Cleaner Production 144:323-333. https://doi.org/10.1016/j.jclepro.2017.01.005

Ferrara I, Missios P, Yildiz HM (2014) Inter-regional competition, comparative advantage and environmental federalism. The Canadian Journal of Economics 47(3):905-952. https://doi.org/10.1111/caje.12098

Fredriksson PG, Wollscheid JR (2014) Environmental decentralization and political centralization. Ecological Economics 107:402-410. https://doi.org/10.1016/j.ecolecon.2014.09.019

Fslleth EI, Hovik S (2009) Local government and nature conservation in Norway: Decentralization as a strategy in environmental policy. Local Environment 14(3):221-231. https://doi.org/10.1080/13549830802692849

Goel RK, Mazhar U, Nelson MA, et al (2017) Different forms of decentralization and their impact on government performance: micro-level evidence from 113 countries. Economic Modelling 62:171-183. https://doi.org/10.1016/j.econmod.2016.12.010

Gray W, Shadbegian R (2004) Optimal pollution abatement: whose benefits matter and How Much. Journal of Environmental Economics and Management 47:510-534. https://doi.org/10.1016/j.jeem.2003.01.001

Halkos GE, Tzeremes NG (2013) Carbon dioxide emissions and governance: A nonparametric analysis for the G20. Energy Economics 40(2):110-118. https://doi.org/10.1016/j.eneco.2013.06.010

Han C (2018) Analysis of the influence of technological progress on industrial carbon emissions in China. Journal of Dalian University of Technology 39(2):65-73. (In Chinese) https://doi.org/10.19525/j.issn1008-407x.2018.02.010

He QC (2015) Fiscal decentralization and environmental pollution: evidence from Chinese panel data. China Economic Review 36:86-100. https://doi.org/10.1016/j.chieco.2015.08.010

Hossein H, Kaneko S (2013) Can environmental quality spread through institutions. Energy Policy 56 (2):312-321. https://doi.org/10.1016/j.enpol.2012.12.067

Huang SF (2017) A study of impacts of fiscal decentralization on smog pollution. World Economy 40(2):127-152. (In Chinese)_CNKI: SUN: SJJJ.0.2017-02-007

Jacobsen GD, Kotchen MJ, Vandenbergh MP (2012) The behavioral response to voluntary provision for an environmental public good: Evidence from residential electricity demand. European Economic Review 56(5):946 - 960. https://doi.org/10.1016/j.euroecorev.2012.02.008

Kunce M, Shogren J (2007) Destructive interjurisdictional competition firm, capital and labor mobility in a model of direct emission control. Ecological Economics 60(3):543-549. https://doi.org/10.1016/j.ecolecon.2005.04.024

Li GS, Han MC (2015) Fiscal decentralization, spatial spillover and China's urban haze pollution: Mechanism and evidences. Contemporary Finance \& Economics 6:26-34. (In Chinese) https://doi.org/10.13676/j.cnki.cn36-1030/f.2015.06.004

Li Q (2018) Emission reduction effect of environmental decentralization: from the perspective of the river chief system. Industrial Economy Research 3:53-63. (In Chinese) https://doi.org/10.13269/j.cnki.ier.2018.03.005

Li XJ, Liu H (2016) Fiscal decentralization and the plight of regional environmental pollution based on the perspective of regional differences-the analysis on the pollutant properties of spillover. Finance and Trade Economy 2:41-54. (In Chinese) https://doi.org/10.19795/j.cnki.cn11-1166/f.2016.02.004 
Liu JJ, Shi D, Wang C (2015) A study on spatial spillover and correlation effect of carbon emissions across 30 provinces in China. Journal of Natural Resources 30(8):1289-1303. (In Chinese) https://doi.org/10.11849/zrzyxb.2015.08.005

Liu XZ, Gao CC, Zhang Y (2018) Spatial dependence pattern of carbon emission intensity in China's provinces and spatial heterogeneity of its influencing factors. Scientia Geographica Sinica 38(5):681-690. (In Chinese) https://doi.org/10.13249/j.cnki.sgs.2018.05.005

Long S, Hu J (2014) Environmental pollution from the perspective of government-enterprise collusion: Theoretical and empirical analysis. Journal of Finance and Economic 40(10):131-144. (In Chinese) https://doi.org/10.16538/j.cnki.jfe.2014.10.001

Lopez R, Mitra S (2000) Corruption, pollution and the Kuznets Environment Curve. Journal of Environmental Economics and Management 40:137-150. https://doi.org/10.1006/jeem.1999.1107

Lu FZ, Yang HC (2019) Environmental decentralization, local government competition and China's ecological environment pollution. Industrial Economics Research 4:113-126. (In Chinese) https://doi.org/10.13269/j.cnki.ier.2019.04.010

Lu YQ, Zhang DG (2016) Environmental decentralization, market segmentation and carbon emissions. China Population Resources and Environment 26(6):107-115. (In Chinese) https://doi.org/10.3969/j.issn.1002-2104.2016.06.014

Luo B, Ling HC (2020) The internal mechanism of environmental decentralization and regional economic growth: based on the adjustment of central-local relationship. Journal of Yunnan University of Finance and Economics. (In Chinese) https://doi.org/10.16537/j.cnki.jynufe.000544

Maddison D (2006) Environmental Kuznets curves: A spatial econometric approach. Journal of Environmental Economics and Management 51:218-230. https://doi.org/10.1016/j.jeem.2005.07.002

Oates WE, Schwab RM (1988) Economic competition among jurisdictions: Efficiency enhancing or distortion inducing. Journal of Public Economics 35(3):333-354. https://doi.org/10.1016/0047-2727(88)90036-9

Oyono PR (2005) Profiling local-level outcomes of environmental decentralizations: the case of Cameroon's forests in the Congo Basin. Journal of Environment and Development 14(2):1-21. https://doi.org/10.1177/1070496505276552

Peng X (2016) Is environmental decentralization conducive to industrial green transformation in China? - Dynamic spatial effect test under the perspective of upgrading of industrial structure. Industrial Economy Research 2:21-31. (In Chinese) https://doi.org/10.13269/j.cnki.ier.2016.02.003

Poon J, Casas I and He C (2006) The impact of energy, transport and trade on air pollution in China. Eurasian Geography and Economics 47(5):568-584. https://doi.org/10.2747/1538-7216.47.5.568

Qi Y, Lu HY, Xu YK (2014) Research on reformation of China's environmental decentralization system: institutional change, numerical estimates and effects assessment. China Industrial Economics 1:31 - 43. (In Chinese) https://doi.org/10.19581/j.cnki.ciejournal.2014.01.003

Ran QY, Zhang JN, Hao Y (2020) Does environmental decentralization exacerbate China's carbon emissions? Evidence based on dynamic threshold effect analysis. Science of the Total Environment 721:1-12. https://doi.org/10.1016/j.scitotenv.2020.137656

Tan ZX, Zhang YY (2015) An empirical research on the relation between fiscal decentralization and environmental pollution. China Population Resources and Environment 25(4):110-117. (In Chinese) https://doi.org/10.3969/j.issn.1002-2104.2015.04.014

Tian JG, Wang YH (2018) Spatial spillover effects between fiscal decentralization, local government's competition and carbon emissions. China Population Resources and Environment 28(10):36-44. (In Chinese) https://doi.org/10.12062/cpre.20180511

Wang J, Zhang KZ (2014) Fiscal decentralization, officials and carbon emission: Evidence from the secretary of the CPC provincial committee and provincial governor. Modern Finance and Economics 34(9):3-14. (In Chinese) https://doi.org/10.19559/j.cnki.12-1387.2014.09.001

Xiao R, Li YY (2014) Fiscal decentralization, financial expenditure and carbon emissions. Soft Science 28(4):21 - 24. (In 
Xue G, Pang XZ (2012) An empirical analysis on the impact of fiscal decentralization on environmental pollution in China.

China Population Resources and Environment 22(1):1-7. $\quad$ (In $\quad$ Chinese)
https://doi.org/10.3969/j.issn.1002-2104.2012.01.013

Zhang H, Feng C, Liu GC (2017) Chinese-style environmental federalism: a study on the effect of environmental decentralization on carbon emissions. Journal of Financial and Economics 43(9):33-49. (In Chinese) https://doi.org/10.16538/j.cnki.jfe.2017.09.003

Zhang HY, Wang W (2020) Threshold effect of China's industrial structure on carbon emissions: Based on provincial panel data. Southern Journal 4:41-43. (In Chinese) https://doi.org/10.3969/j.issn.1004-1133.2020.04.013

Zhang K, Zhang Z, Liang Q (2017) An empirical analysis of the green prardox in China: from the perspective of fiscal decentralization. Energy Policy 103:203-211. https://doi.org/10.1016/j.enpol.2017.01.023

Zhang KZ, Wang J, Cui XY (2011) Fiscal decentralization and environmental pollution: from the perspective of carbon emission. China Industrial Economics 10:65-75. (In Chinese) https://doi.org/10.19581/j.cnki.ciejournal.2011.10.007

Zhang WJ, Ye AZ (2017) Research on the carbon emission perspective of environmental benefits of fiscal decentralization - based on semi-parametric panel of spatial lag model. Soft Science 31(1):72-75. (In Chinese) https://doi.org/10.13956/j.ss.1001-8409.2017.01.16

Zhu Q, Peng XZ, Lu ZM (2010) Analysis model and empirical study of impacts from population and consumption on carbon emissions. China Population Resources and Environment 20(2):98-102. (In Chinese) https://doi.org/10.3969/j.issn.1002-2104.2010.02.017

Zou X, Lei C, Hu C (2019) Environmental decentralization and regional green development. China Population Resources and Environment 29(6):97-106. (In Chinese) https://doi.org/10.12062/cpre.20190116 